"This is an Accepted Manuscript of an article published by Polymers for Advanced technologies (PAT), vol 133, no 42, in August 2016."

\title{
Designing Polymeric Sensing Materials: What are we Doing Wrong?
}

Katherine M. E. Stewart and Alexander Penlidis*

Institute for Polymer Research, Department of Chemical Engineering, University of Waterloo, 200 University Avenue West, Waterloo, Ontario, N2L 3G1, Canada

E-mail: penlidis@uwaterloo.ca

Keywords: Sensing Mechanisms; Gas Sensors; Polymer Sensing Materials; Dopants; Volatile Organic Compounds (VOCs)

\section{Abstract}

Gas analytes, or volatile organic compounds (VOCs), interact with polymeric sensing materials through various sensing mechanisms. The dominant sensing mechanisms are discussed for different types of VOCs, which are categorized by their functional groups. Based on these sensing mechanisms, a systematic approach is used to design and tailor polymeric sensing materials for specific analytes and applications. This approach also takes into consideration other constraints determined by the target application. We include practical prescriptions on how to efficiently and cost-effectively design, tailor, and select potential polymeric sensing materials, as well as how to evaluate these sensing materials.

\section{Introduction}

Monitoring volatile organic compounds (VOCs) is important in many applications. For example, formaldehyde and benzene contribute to poor indoor air quality; ${ }^{[1]}$ acetone or ethanol in a person's breath may indicate disease ${ }^{[2]}$ or intoxication, ${ }^{[3]}$ respectively; and methane contributes to the greenhouse effect. ${ }^{[4]}$ Typically, VOCs need to be detected at very low (ppm or lower) concentrations and to do so requires very sensitive sensors.

The "heart" of a sensor is the sensing material since that is what interacts with the analytes. Changing the sensing material will change which analytes are able to interact with the sensing material to produce a response. Since multiple analytes are usually present in a specific environment, a sensor (and thus, sensing materials) must be able to either only target a specific 
analyte (highly selective) ${ }^{[5]}$ or identify and differentiate between multiple analytes, such as in an electronic nose or sensor array. ${ }^{[6]}$

Currently, many new sensing materials are created through a materials science approach where a copolymer or polymer composite is made. Then these materials are evaluated as potential sensing materials, for which applications are then sought after. These materials are characterized using techniques such as scanning electron microscopy (SEM), transmission electron microscopy (TEM), and X-Ray Diffraction (XRD), and are subsequently deposited onto a commercially available sensor. ${ }^{[7,8]}$ Often, these materials are only evaluated for one gas analyte. ${ }^{[9]}$ This approach can be very time consuming and expensive.

This paper focuses on a more systematic and direct approach that begins with the target analyte and putative application. In doing so, the sensing material is designed and modified for a target analyte. This approach takes into consideration different constraints imposed by the target application, creating viable sensing materials. The most important aspects for a sensing material are sensitivity (related to the detection limit) and selectivity (the ratio of the response to the target analyte to the response of an interferent analyte); ${ }^{[10]}$ however, other constraints must also be considered.

These constraints include the operating environment (and material stability), sensor type, and detection limit required for the target application. The operating environment affects the operational temperature and the type and concentrations of all gas analytes present. The sensor type affects the type of sensing material required (e.g. a conductive sensing material is needed for a resistive type sensor) and the response and recovery times of the sensor.

This paper focuses on how polymeric sensing materials interact on a mechanistic level with specific VOCs. Multiple sensing mechanisms are explained in Section 2. To better understand how polymeric sensing materials interact with different types of VOCs, the VOCs have been categorized by their functional groups and the dominant mechanisms for each category are examined, using sensing materials from the literature. In addition, case studies (examples and counterexamples) with experimental work have been employed to demonstrate and support this approach, leading to practical guidelines for choosing potential sensing materials.

This extensive paper is based on the recent Stewart and Penlidis brief conference publication. ${ }^{[11]}$ The current paper includes more sensing mechanisms (both primary and secondary mechanisms) and describes the dominant sensing mechanisms for a variety of functional groups. In addition, practical (general) prescriptions are suggested that can be used to narrow down potential polymeric sensing materials for an assortment of target analytes.

\section{Sensing Mechanisms}




\section{Primary Effects}

Primary sensing mechanisms are what attract or repel an analyte to a sensing material. All of these effects are electrostatic in nature. Polarity, Lewis acid-base interactions, and metal coordination all attract analytes based on electrostatic forces. Steric hindrance, on the other hand, is a repulsive force that pushes analytes away from a sensing material.

\section{Polarity and Hydrogen Bonding}

A covalently bound compound may either be polar or non-polar (assuming a net charge of zero on the molecule). The polarity is based on whether some atoms within a molecule disproportionately draw electron density towards themselves. Atoms with high electronegativities, such as nitrogen (3.0), oxygen (3.5), and fluorine (4.0), draw electron density of nearby atoms that are less electronegative, such as carbon (2.55) and hydrogen (2.1) towards themselves. If a disproportionate amount of electron density surrounds one or more atoms, then it results in the molecule having a slightly more negative charge on the electron dense atom(s) and a slightly positive charge on the electron deficient atoms, which results in an overall charge distribution (or dipole moment) on the molecule. This is known as a polar molecule. ${ }^{[1]}$ For reference, Table 1 includes the dipole moments of common VOCs. The higher the dipole moment, the larger the charge difference on the molecule; and thus the more polar the molecule.

Table 1. Dipole Moment of Common Volatile Organic Compounds (VOCs)

\begin{tabular}{c|c}
\hline Analyte & Dipole Moment (D) \\
\hline Methane & 0.00 \\
Ethane & 0.00 \\
Benzene & 0.00 \\
Toluene & 0.36 \\
Ethylbenzene & 0.58 \\
Xylene & 0.64 \\
Triethylamine & 0.87 \\
Dichloromethane & 1.14 \\
Chloroform & 1.15 \\
Phenol & 1.22 \\
Formic Acid & 1.41 \\
Ammonia & 1.42 \\
Tetrahydrofuran & 1.63 \\
Isopropanol & 1.66 \\
Ethanol & 1.69 \\
Methanol & 1.70
\end{tabular}




\begin{tabular}{c|c}
\hline Acetic Acid & 1.74 \\
Ethyl Acetate & 1.78 \\
Water & 1.85 \\
Ethylene Glycol & 2.28 \\
Formaldehyde & 2.33 \\
Acetaldehyde & 2.70 \\
Acetone & 2.91 \\
Acetonitrile & 3.92 \\
\hline
\end{tabular}

The geometry of a molecule is also important. A perfectly symmetric molecule, such as a tetrahedral shape where all four atoms/functional groups surrounding a central atom are identical, is non-polar since the overall charge on the molecule is zero. For example, carbon tetrachloride $\left(\mathrm{CF}_{4}\right)$ has a charge distribution between the carbon (2.55) and each fluorine (4.0) atom, where the fluorine draws electron density away from the carbon. But since this occurs in four equally opposite directions, due to the tetrahedral shape, the net charge on $\mathrm{CF}_{4}$ is zero (no dipole) and thus, $\mathrm{CF}_{4}$ is non-polar. Other symmetric geometries include linear $\left(\mathrm{CO}_{2}\right)$, trigonal planar $\left(\mathrm{BF}_{3}\right)$, trigonal bipyramidal $\left(\mathrm{PF}_{5}\right)$, and octahedral $\left(\mathrm{SF}_{6}\right)$.

Non-polar molecules have a dipole moment of less than $0.4 \mathrm{D}$. This is why hydrocarbons, which contain only hydrogen and carbon, are non-polar, despite a small difference in electronegativities ( 2.55 for carbon and 2.2 for hydrogen). The dipole created between the hydrogen and carbon atoms is considered negligible. In addition, many hydrocarbons are symmetric and have an overall net dipole of zero, as is the case for linear alkanes. ${ }^{[12]}$

Two polar molecules are attracted to one another through electrostatic forces. The more polar the molecules, the stronger the attraction. A special case of this is called hydrogen bonding. This occurs when a highly electronegative atom, nitrogen (3.0), oxygen (3.5), or fluorine (4.0), is bound to a hydrogen (2.2). This large electronegativity difference results in the nitrogen, oxygen, or fluorine atom stealing most of the electron density away from the hydrogen atom and thus, a large dipole is created. This results in electrostatic forces strong enough to create a weak (physical) bond between the hydrogen of one molecule and the nitrogen, oxygen, or fluorine of another molecule. For example, polyaniline (PANI) is able to hydrogen bond to alcohols, such as methanol. The amine $(\mathrm{NH})$ in PANI is able to hydrogen bond to the alcohol $(\mathrm{OH})$ in methanol. ${ }^{[13]}$

\section{Lewis Acid-Base Interactions}

A Lewis acid-base interaction occurs when a Lewis acid binds to a Lewis base. A Lewis acid is characterized as an electron deficient atom, such as a positively charged hydrogen or carbon atom. A Lewis base contains at least one lone pair of electrons, such as on an oxygen or nitrogen atom. The Lewis base behaves as a nucleophile, and seeks out (attacks) an electron deficient 
atom with which to donate a lone pair of electrons. This donation is not "complete", in that the electron density is shared between the two molecules and thus, a weak physical bond is formed.

For example, acetaldehyde contains a double bonded oxygen atom that has two pairs of lone electrons that are capable of behaving as a Lewis base. One pair of electrons is able to bond to a Lewis acid, such as an electron-deficient carbon. The electron deficient carbon must also be sterically unhindered (see Section 2.1.5), in that the Lewis base must be able to get close enough to bond. The electron deficient carbons in aldehydes and ketones, which have a trigonal planar geometry, are very susceptible to nucleophilic attack since there is little steric hindrance that repels the nucleophile. The carbon attached to a double bonded oxygen atom is electrondeficient (since the oxygen draws the carbon's electrons away from the carbon and towards itself), such as that in methyl methacrylate. Both aldehydes and ketones can behave as a Lewis acid (deficient carbon) and Lewis base (lone pairs on the double bonded oxygen). Similarly, methyl methacrylate can also behave as a Lewis acid or base. Therefore, the addition of methyl methacrylate to a sensing material for acetaldehyde may improve the sensitivity to acetaldehyde. ${ }^{[14]}$

\section{p-orbitals and $\pi$-bonds}

Volatile organic compounds (VOCs) and carbon-based polymers all contain p-orbitals since many of the atoms (i.e. carbon, nitrogen, and oxygen) covalently bond using p-orbitals. If a porbital is covalently bound, the pair of electrons is shared between two atoms and cannot be further shared with another molecule. The p-orbitals of interest are those with a lone pair of electrons, as in the case of nitrogen (one pair) and oxygen (two pairs), assuming a neutral charge on the atom. These lone pairs can behave as Lewis-bases (as described in Section 2.1.2), but they can also become delocalized in certain cases. In addition, the p-orbitals that are shared in double bonds (e.g. $\mathrm{C}=\mathrm{C}$ ), can also become delocalized in specific cases such as in conjugated systems, discussed below.

Alternating single and double bonds in a molecule result in an overlap of p-orbitals (or $\pi$-bonds). This alternation of single and double bonds in a ring produces an aromatic compound. Delocalization of electrons across $\pi$-bonds occurs due to this overlap of p-orbitals and allows electrons to travel freely between multiple atoms. This delocalization of electrons results in the formation of a so-called 'conjugated system'. Aromatic rings, such as benzene, are a prime example of structures that can delocalize electrons; however, delocalization can also occur along linear chains. This delocalization results in lower energy, and therefore, more stable molecules.

$\pi$-bonds will overlap with one another if given the opportunity. Since the electrons in $\pi$-bonds are delocalized across p-orbitals (Figure 1), $\pi$-bonds are able to easily interact with other molecules that contain p-orbitals oriented in the same direction, which results in stacking of 
aromatic rings and other $\pi$-bonds. ${ }^{[15]}$ Overlap can occur when the energy of the p-orbitals in one molecule is similar to the energy of the p-orbitals in another. $\pi$-bonds commonly occur across carbon atoms, which have the same energies since they are the same atom; however, other atoms that are bound to these carbons can change energy levels of the orbital of the electrons available to bind.
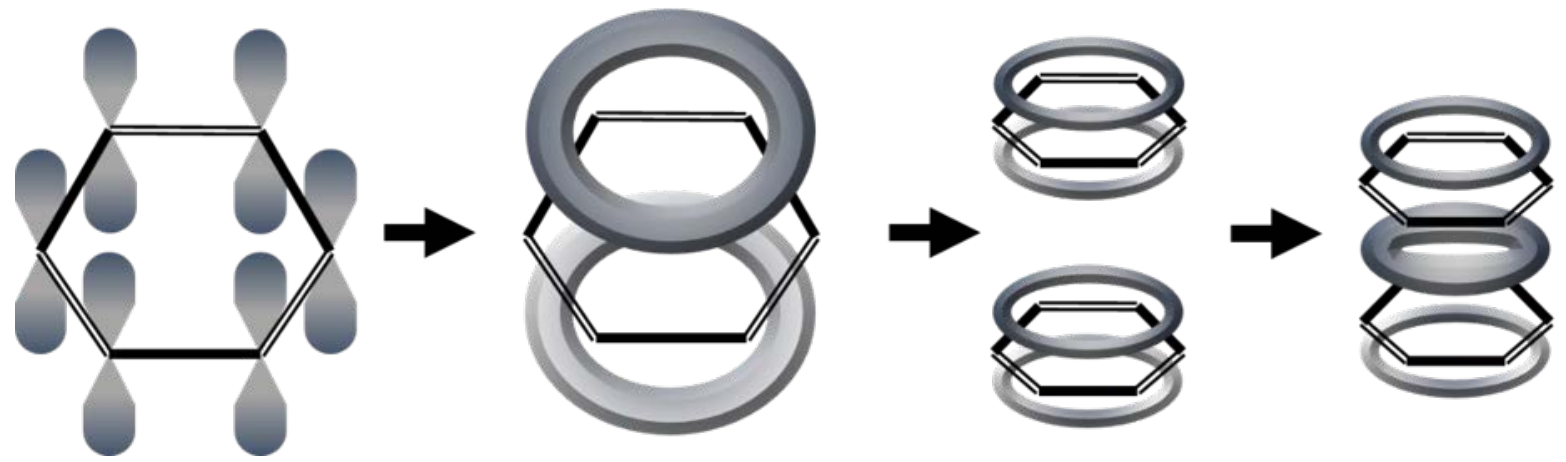

Figure 1. Overlap of p-orbitals and $\pi$-bonds.

It is also possible for other p-orbitals to stack with $\pi$-bonds, since $\pi$-bonds are delocalized porbitals. If the p-orbitals are oriented in the appropriate geometry, then $\pi$-bonds are able to stack on top of the p-orbitals, as they would stack on $\pi$-bonds. For example, three fluorine atoms on a carbon have p-orbitals capable of this. Each fluorine atom has a p-orbital in the z-direction, which is not used in bonding with the carbon. These p-orbitals (one on each of the fluorine atoms) are oriented in a trigonal planar geometry, essentially appearing as a ring. This planar geometry of the p-orbitals is perfect for $\pi$-bonds stacking on p-orbitals.

\section{Metal Coordination}

Metal coordination only exists as a sensing mechanism when a metal oxide is present in the sensing material. Coordination between an analyte and a metal is what allows basic catalysis to occur. Therefore, if an analyte is catalyzed by a specific metal oxide, such as platinum (Pt) used to oxidize methanol, then that metal oxide may improve the sensing properties (sensitivity and selectivity) of a polymeric sensing material. ${ }^{[16,17]}$

Metal and metal oxides are commonly used as sensing materials and typically work on the basis of catalyzing (facilitating) an oxidation reaction. A typical mechanism is shown below (see Equations 1 -6). A similar mechanism occurs for the oxidation of any small organic molecule, where the oxygen gas $\left(\mathrm{O}_{2}\right)$ comes from air and adsorbs to the surface of the metal or metal oxide (catalyst) ${ }^{[18]}$

$\mathrm{O}_{2 \text { (gas) }} \leftrightarrow \mathrm{O}_{2 \text { (adsorbed) }}$

Equation 1

$\mathrm{O}_{2 \text { (adsorbed) }}+\mathrm{e}^{-} \leftrightarrow \mathrm{O}_{2}{ }^{-}$(adsorbed)

Equation 2 
$\mathrm{O}_{2}^{-}$(adsorbed) $+\mathrm{e}^{-} \leftrightarrow 2 \mathrm{O}_{\text {(adsorbed) }}^{-}$

Equation 3

$\mathrm{O}^{-}$(adsorbed) $+\mathrm{e}^{-} \leftrightarrow \mathrm{O}_{2}^{-}$(adsorbed)

Equation 4

$\mathrm{HCHO}_{\text {(gas) }} \leftrightarrow \mathrm{HCHO}_{\text {(adsorbed) }}$

Equation 5

$\mathrm{O}_{2}{ }^{-}$(adsorbed) $+\mathrm{HCHO}_{\text {(adsorbed) }} \leftrightarrow \mathrm{H}_{2} \mathrm{O}_{\text {(adsorbed) }}+\mathrm{CO}_{2 \text { (adsorbed) }}+4 \mathrm{e}^{-}$

Equation 6

Oxidation utilizes the partial pressure of oxygen in the atmosphere. The oxygen is adsorbed onto the surface of the sensing material. As oxidation takes place, electrons $\left(\mathrm{e}^{-}\right)$are created that reduce the resistance of the sensor. This change in resistance is monitored as the sensor response. Very small amounts of other metals and metal oxides can be added to the sensing material to increase the amount of adsorbed oxygen onto the surface, thereby improving the sensitivity of the sensor. ${ }^{[19]}$

When metal and metal oxides are incorporated into a polymer, the amount of adsorbed (or coordinated) oxygen onto the metal is significantly reduced due to reduced access of oxygen to the metal. This reduced access is caused by two things. First, there is a reduced amount of coordination sites on the metal since the polymer is occupying some of the coordination sites (hence the metal, for instance, nickel (Ni), is bound to the polymer; see Figure 2). Second, the steric hindrance caused by the polymer repels some of the oxygen molecules so that the oxygen is not able to get close enough to coordinate to the metal. ${ }^{[20]}$

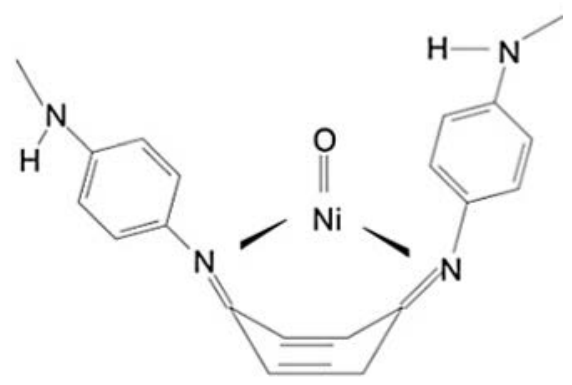

Figure 2. Ni coordination to the nitrogens in the quinoid ring. ${ }^{[20]}$

The geometry is important to consider when the metal or metal oxide is incorporated into a polymeric sensing material. The addition of a metal or metal oxide will cause the polymer to coordinate around the metal, creating a 'kink' (or change in conformation) in the polymeric chain (see Figure 2). This reduces the number of available spots for analyte coordination and also causes a steric interaction that creates a cavity within the polymer, which can improve the sorption of an analyte into the polymer. 
Coordination of the polymer also, generally, creates strain on the bonds within the polymer, since the polymer bends (or changes conformation) to bind to the metal. The preferred conformation of an aromatic ring is a flat plane. This strain can be seen in Figure 2 by the "boat" conformation (the aromatic ring has been bent into the shape of a "boat", with two carbons bent upwards) that is created when polyaniline (PANI) coordinates to the Ni. To bend into the "boat" conformation, the double bonds in the carbon ring have moved (the electron density has shifted) to allow the carbon to bend. If too much metal is added as a dopant, the polymer chains will become too strained and begin to break, thereby significantly reducing the benefit of the addition of the metal or metal oxide dopant.

It should also be noted that the metal oxide may not actually incorporate itself into the polymer because the strain is too great for the polymer to conform around the metal oxide. For example, poly (2,5-dimethyl aniline) (P25DMA) is unable to coordinate with zinc oxide ( $\mathrm{ZnO})$. In this case, the $\mathrm{ZnO}$ was added during the polymerization of P25DMA and resulted in minimal polymer formed around the $\mathrm{ZnO}$ nanoparticles because the strain was too great and the polymer chains could not withstand the strain caused by conforming around the $\mathrm{ZnO} .^{[21]}$

\section{Steric Hindrance}

The previous four primary effects are all attractive forces that draw an analyte towards the sensing material. Steric hindrance, on the other hand, is a repulsive force. Each atom is surrounded by an electron cloud that repels other atoms. Therefore, the larger (and bulkier) the molecule, the larger the electron cloud. However, the geometry of a molecule plays a role as well.

Steric hindrance is caused by the electronic repulsion of the electrons on molecules. All molecules are surrounded by a cloud of electrons that repel the molecule in question from other molecules. The bulkier a molecule (analyte), the larger the electronic cloud that surrounds it and therefore, the harder it is for that molecule to come near another molecule or fit into an interstitial space of a sensing material. Therefore, smaller, less bulky analytes (such as formaldehyde or methanol) are able to interact with a sensing material more easily than larger, bulkier analytes (such as triethylamine). This, as a result, can improve the selectivity of a sensing material.

Note that as more atoms are added onto the side group, the electron cloud gets larger. A t-butyl group (three methyl groups off one carbon atom) is much larger than hydrogen and therefore, exhibits more repulsion due to a larger electron density. A t-butyl group also requires more space due to the increased number of atoms and is therefore, a very bulky side group. Due to the bulkiness of t-butyl, it is much more difficult for an analyte to reach the central carbon. This can be thought of as the t-butyl group protecting the central carbon. This can be used to an advantage in sensing materials by excluding (and thus "protecting” the sensing material from) 
larger analytes, similar to a molecular sieve. The bulkiness can also be used to increase interstitial spaces or cavities in a sensing material to improve access of the analyte into the sensing material, thereby improving sensitivity.

\section{Dispersion and van der Waals Forces}

Electron density shifts around an atom and appears to have an average symmetric distribution around an atom; however, at any given time, the electron density may be greater on one side of an atom or compound. This results in a slight negative charge on that side and a slight positive charge on the opposite side. These charges last very briefly, but are enough to induce small electrostatic forces that bring molecules together in close proximity.

Dispersion and van der Waals forces are the result of induced dipoles created when two molecules come into close proximity. These induced dipoles are stabilized by electrostatic forces created with one molecule being slightly positive and the other slightly negative, where the two molecules are "touching". The electron density does not shift between the two molecules, just around each molecule, such that one side of the molecule is positive and the other side is negative. ${ }^{[22]}$

\section{Secondary Effects}

Secondary sensing mechanisms are effects that occur once the analyte is in close proximity to the sensing material. These effects are not what initially attracts the analyte to the sensing material; however, these secondary effects can also contribute considerably and often appear as part of the dominant mechanism.

\section{Swelling}

Absorption of an analyte (or multiple analytes) can reach a point where the analyte(s) pushes the polymer chains away from one another. When this happens, the polymer swells, increasing in overall volume. It should be noted that swelling of a conductive polymer, which is typically in a glassy state at room temperature, is expected to be low; however, swelling has been observed for multiple conductive polymers. ${ }^{[23]}$

Polymer swelling can affect the response in different ways. For example, when water absorbs into polyaniline (PANI), swelling increases the resistance (reduces the conductivity); however, when water absorbs into polypyrrole (PPy), swelling reduces the resistance (increases the conductivity). ${ }^{[24]}$ 
PANI's conductivity is related to its conjugation and defects along the polymer chain and the conjugation between the polymer chains. When water molecules are absorbed into PANI, initially the water increases the conductivity by increasing the number of defects and altering the conjugation along the polymer chains. However, when too much water is absorbed, the water molecules push the polymer chains further apart, resulting in the polymer swelling, and reducing the amount of conjugation between polymer chains. This means that it is more difficult for a charge to be carried across multiple polymer chains, thus resulting in a decrease in PANI's conductivity. ${ }^{[24]}$

Conversely, the absorption of water molecules into PPy initially causes a reduction in conductivity because the water molecules increase the space between polymer chains, causing minor swelling. This reduces the charge transfer between polymer chains and thus, conductivity as well. However, as the concentration of water increases, a threshold is reached and the conductivity of PPy begins to increase with an increase in water concentration. This may be due to the water molecules forming a continuous layer between the PPy chains, effectively creating a charge transfer bridge between the conductive PPy chains. ${ }^{[24]}$

\section{Solvent Effects}

Swelling of a polymer may lead to solvent effects, where the analyte sorbs and diffuses into the polymer matrix to the point at which the analyte begins to behave as a "solvent". When this occurs, the polymer chains become mobile. For conductive polymers, this may result in a decrease in conductivity because electrons may no longer be able to jump from one chain to another. $^{[25]}$ However, the solvation of the polymer chains increases the conductivity if the solvent (analyte) has a higher electrical permittivity than the polymer. ${ }^{[26]}$

\section{Multiple Mechanisms}

Multiple mechanisms occur, sometimes simultaneously, when a gas analyte interacts with a sensing material. Some of these mechanisms may be the result of (triggered by) other mechanisms. For example, an analyte may be attracted to a polymer and sorb by hydrogen bonding or Lewis acid-base interactions. As more analyte sorbs, the sensing material begins to swell. This changes the properties of the sensing material and may result in more analyte sorbed than would be otherwise. In a sense, the partitioning characteristics of the target analyte change between the bulk phase and the polymer (interaction/sensing) sites. This, of course, affects the diffusivity characteristics of the analyte, whereby the movement of the polymer chains, as the sensing material swells, results in a change of pore size and distribution and thus, a corresponding change in the diffusion of the analyte into the sensing material. Swelling can also lead to solvent effects, whereby the analyte concentration has passed a threshold and begins to behave more like a "solvent" than an analyte. 
In a crystalline polymer, as an analyte is sorbed, it enters the larger pores first. Many pores are interconnected and the analyte continues to move (diffuse) into the polymer with ease until all of these larger pores are saturated. Once these pores are saturated, the analyte can continue to migrate into smaller pores as the analyte begins to behave as a "solvent", which results in some polymer chain mobility. As the chains move, some of the smaller pores are widened, which intensifies the solvent effects. This also results in further swelling of the polymer (and enhanced sorption). Eventually, the polymer is not able to swell any further, which results in no more analyte being able to sorb into the polymer since saturation has been reached. ${ }^{[27]}$ At that point, no more analyte can be sorbed onto the polymer and thus, the maximum limit (highest concentration) of how much analyte can be detected has been reached.

\section{Solubility and Solubility Parameters}

Solubility, in general, is the ability of one substance to mix with another. Solubility between a solute and a solvent ranges from fully miscible, such as ethanol and water, to essentially insoluble, such as silver chloride in water. For gas sensors, the solubility of the target gas analyte, and the interferents in the sensing material, particularly in the polymeric sensing material, is important. If the gas analytes are even somewhat soluble in the sensing material, then the gas analyte is able to diffuse into the sensing material, thereby increasing the amount of analyte that is able to bind and ultimately produce a measurable response.

Many factors affect the solubility of a substance in another substance; for example, the polarity of the two substances. The general rule is that polar molecules dissolve in other polar molecules and non-polar molecules dissolve in non-polar ones; however, solubility is much more complicated since other factors, not just polarity, influence a molecule’s solubility.

Solubility parameters are useful indicators in assessing whether two molecules are miscible since they are based on both a molecule's chemical structure and physical state. Each substance (molecule) has a solubility parameter that in essence summarizes the forces with which the substance is likely to interact with another substance, given the substance's chemical nature and state. If the solubility parameters of two substances are similar, then they are likely soluble in one another.

It should be noted that these solubility parameters are either determined experimentally (where some error is always present) or calculated based on models (that always use certain approximations and assumptions). This often results in discrepancies between solubility parameters published in the literature.

There are two types of solubility parameters, the Hildebrand solubility parameter $(\delta)$ and the Hansen solubility parameters $\left(\delta_{\mathrm{D}}, \delta_{\mathrm{P}}, \delta_{\mathrm{H}}\right)$. The Hildebrand solubility parameter summarizes the 
different contributions to the cohesive energy density (CED) function of the specific substance and therefore, some information about solubility is lost. On the other hand, the Hansen solubility parameters break down the CED of a substance into three types of contributions: dispersive energy $\left(\delta_{\mathrm{D}}\right)$, polarity $\left(\delta_{\mathrm{P}}\right)$, and ability to hydrogen bond $\left(\delta_{\mathrm{H}}\right)$; see Tables 2 and 3 . The Hildebrand and Hansen solubility parameters are related as per Equation 7.

$\delta^{2}=\delta_{D}^{2}+\delta_{p}^{2}+\delta_{h}^{2}$

Equation 7

In general, if two compounds have similar Hildebrand parameters, then they are likely to dissolve within one another. For example, acetone $\left(19.9 \mathrm{MPa}^{1 / 2}\right)$ and aniline $\left(21.1 \mathrm{MPa}^{1 / 2}\right)$ should be fairly miscible due to their similar solubility parameters. However, due to the simplification of the calculation, this is not always the case. For instance, toluene (18.2 $\mathrm{MPa}^{1 / 2}$ ), which is not capable of hydrogen bonding, has an identical Hildebrand parameter to ethyl acetate (18.2 $\mathrm{MPa}^{1 / 2}$ ), which is capable of hydrogen bonding. However, their Hansen Solubility parameters are quite different (see Table 2). ${ }^{[22]}$

Therefore, the Hansen solubility parameters, which break down the solubility into dispersive energy $\left(\delta_{\mathrm{D}}\right)$, polarity $\left(\delta_{\mathrm{P}}\right)$, and ability to hydrogen bond $\left(\delta_{\mathrm{H}}\right)$ contributions will give a better indication. If these three parameters are close in nature (i.e. when plotted against one another, the two substances are located close in the 3-D space), then the two substances are likely to be soluble. For example, benzene and chloroform have similar Hildebrand solubility parameters (18.6 $\mathrm{MPa}^{1 / 2}$ and $19.0 \mathrm{MPa}^{1 / 2}$, respectively), but different Hansen solubility parameters (see Table 2), whereas benzene and toluene have similar Hildebrand and Hansen solubility parameters.

Note that the $\delta_{\mathrm{p}}$ of the Hansen solubility parameters for benzene is not zero (see Table 2), despite benzene being non-polar. This is because the electron density is constantly shifting across the atoms in a molecule, even in non-polar molecules, such as benzene. This can result in a small polarity for a brief moment, and thus have a non-zero polarity solubility parameter. ${ }^{[33]}$ Therefore, an aromatic molecule such as benzene, which contains delocalized electrons, has a $\delta_{\mathrm{P}}$ of 2.0. Non-polar molecules, which cannot exchange electrons, such as butane, have both a $\delta_{\mathrm{P}}$ and $\delta_{\mathrm{H}}$ of zero, as seen in Table 2 .

Table 2. Hansen and Hildebrand Solubility Parameters for Various VOCs

\begin{tabular}{|c|c|c|c|c|}
\hline \multirow{2}{*}{ Analyte } & \multicolumn{3}{|c|}{ Hansen $\left(\mathrm{MPa}^{1 / 2}\right)^{[28]}$} & \multirow{2}{*}{$\begin{array}{c}\text { Hildebrand } \\
\left(\mathrm{MPa}^{1 / 2}\right)^{[28]} \\
\delta\end{array}$} \\
\hline & $\delta \mathbf{D}$ & $\delta_{H}$ & $\boldsymbol{\delta} \mathbf{P}$ & \\
\hline Butane & 14.1 & 0 & 0 & 14.1 \\
\hline Xylene & 17.8 & 1 & 3.1 & 18.0 \\
\hline Ethyl Acetate & 15.8 & 5.3 & 7.2 & 18.2 \\
\hline
\end{tabular}




\begin{tabular}{c|ccc|c}
\hline Toluene & 18 & 1.4 & 2 & 18.2 \\
Benzene & 18.4 & 0 & 2 & 18.6 \\
Chloroform & 17.8 & 3.1 & 5.5 & 19.0 \\
Tetrahydrofuran & 16.8 & 5.7 & 8 & 19.4 \\
Acetone & 15.5 & 10.4 & 7 & 20.1 \\
Dichloromethane & 18.2 & 6.3 & 6.1 & 20.3 \\
Acetaldehyde & 14.7 & 8 & 11.3 & 21.1 \\
Acetic Acid & 14.5 & 8 & 13.5 & 21.3 \\
Phenol & 18 & 5.9 & 14.9 & 24.1 \\
Acetonitrile & 15.3 & 18 & 6.1 & 24.6 \\
Formaldehyde & 12.8 & 14.4 & 15.4 & 24.7 \\
Ethanol & 15.8 & 8.8 & 19.4 & 26.6 \\
Methanol & 15.1 & 12.3 & 22.3 & 29.7 \\
Ethylene Glycol & 17 & 11 & 26 & 32.9 \\
Water & 15.5 & 16.0 & 42.4 & 47.9 \\
\hline
\end{tabular}

Note that the solubility parameters for polymers are simply estimates. Typically, the solubility parameters of a polymer are experimentally obtained by dissolving the polymer in solvents and estimating the solubility of the polymer based on how well the polymer dissolves in different solvents. ${ }^{[34]}$ Thus, typically, only the Hildebrand solubility parameter is available (if a parameter is available at all). Therefore, the Hildebrand solubility parameter is used in the discussion that follows as an indicator of solubility.

In addition, the solubility parameters of a monomer (i.e. aniline) will be different from those of its corresponding polymer (i.e. polyaniline (PANI)), although the values are close. For example, aniline has a Hildebrand solubility parameter of $21.1 \mathrm{MPa}^{1 / 2}$, whereas PANI has a Hildebrand solubility parameter of $22.2 \mathrm{MPa}^{1 / 2}$. ${ }^{35]}$ Therefore, the solubility parameter for the monomer may be used as a very rough guide for that of the corresponding polymer, if the solubility parameter is not available.

Table 3. Hansen and Hildebrand Solubility Parameters for Various Polymers

\begin{tabular}{|c|c|c|c|c|}
\hline \multirow{2}{*}{ Polymer } & \multicolumn{3}{|c|}{ Hansen $\left(\mathrm{MPa}^{1 / 2}\right)^{[28]}$} & \multirow{2}{*}{$\begin{array}{c}\text { Hildebrand } \\
\left(\mathrm{MPa}^{1 / 2}\right)^{[28]} \\
\delta\end{array}$} \\
\hline & $\boldsymbol{\delta} \mathbf{D}$ & $\boldsymbol{\delta}_{\mathbf{H}}$ & $\delta \mathbf{P}$ & \\
\hline Polyethylene & - & - & - & 16.2 \\
\hline Poly (butadiene-co-styrene) & 17.55 & 3.36 & 2.7 & 18.07 \\
\hline $\begin{array}{l}\text { Poly (2,6-dimethyl-1,4-phenylene } \\
\text { oxide) }\end{array}$ & - & - & - & $19.6^{[31]}$ \\
\hline Poly (ethylene oxide) & 17.3 & 3.0 & 9.4 & 19.9 \\
\hline Poly (2,5-dimethyl aniline) & - & - & - & $21^{[29]}$ \\
\hline Poly (vinyl chloride) & 18.72 & 10.03 & 3.07 & 21.46 \\
\hline
\end{tabular}




\begin{tabular}{c|ccc|c} 
Polyaniline & 17.4 & 8.1 & 10.7 & $22.2^{[30]}$ \\
Polystyrene (LG, BASF) & 21.28 & 5.75 & 4.3 & 22.47 \\
Poly (methyl methacrylate) & 18.69 & 10.56 & 7.51 & 22.8 \\
Poly (vinylidene fluoride) & 17.2 & 12.5 & 9.2 & 23.2 \\
Polypyrrole & - & - & - & $25.2^{[32]}$ \\
Poly (vinyl pyrrolidone) & - & - & - & 25.6 \\
Poly (vinyl acetate) & 20.93 & 11.27 & 9.66 & 25.66 \\
Polyethylene & - & - & - & 16.2 \\
\hline
\end{tabular}

Note that the composition of a polymer, including amorphous and crystalline fractions, copolymer composition, and crosslinking, all affect the solubility parameters of a polymer. Table 4 shows five different values observed for the Hildebrand solubility parameter for polystyrene, two values observed for poly (styrene-co-divinylbenzene), and the effect crosslinking has on the solubility parameters of poly (styrene-co-divinylbenzene).

Table 4. Hildebrand Solubility Parameters for Polystyrene

\begin{tabular}{cc}
\hline Polymer & Hildebrand $\left(\mathbf{M P a}^{\mathbf{1} / \mathbf{2}}\right)^{[\mathbf{2 8}]}$ \\
\hline Polystyrene & 17.52 \\
& 20.16 \\
& 18.6 \\
& 18.72 \\
Poly (styrene-co-divinylbenzene) & 18.62 \\
& 17.39 \\
5\% Crosslinking & 14.8 \\
10\% crosslinking & 15.7 \\
20\% crosslinking & 17.8 \\
\hline
\end{tabular}

\section{Dominant Mechanisms for Different Volatile Organic Compounds (VOCs)}

The dominant mechanisms for how different analytes interact are discussed next. The analytes are classified by their functional groups such as alcohols and amines. In total, six different functional groups are discussed in the subsequent subsections (alcohols, aldehydes, alkanes, amines, aromatics, and ketones). At the end of each subsection, a table summarizes various sensing materials used for the detection of the analytes, as well as sensitivity (detection limit) and selectivity (if available). Note that in many of the tables in this section, there are no entries for selectivity. This is due to the fact that very few publications conduct or report any selectivity 
experiments (i.e. most often, only one analyte is used to evaluate the efficacy of a sensing material).

\section{Alcohols}

Alcohols are organic compounds that contain a hydroxyl (-OH) group, such as methanol and ethanol. These small alcohols are polar, due to the oxygen atom pulling electron density towards itself, away from the other atoms in the molecule, making the oxygen more electronegative and the other atoms more electropositive. Alcohols are also able to hydrogen bond because of the large dipole created between the oxygen and hydrogen. Therefore, alcohols are attracted to sensing materials that are polar, especially those able to hydrogen bond.

As an example, polyaniline (PANI) is a common sensing material for both methanol and ethanol. ${ }^{[36-38]}$ PANI contains an amine group that makes it polar and able to hydrogen bond. PANI is also conductive when doped with an acid, which makes it an ideal sensing material in resistive type sensors (see Figure 3a). The doping leads to positive charges on the nitrogen atoms, due to the additional hydrogen sharing electron density from the acid, and creates holes along the polymer chain that allow electrons to hop from one to another, thus making PANI conductive. ${ }^{[39]}$ These positive charges also more strongly attract electronegative atoms and molecules, such as the oxygen in methanol and ethanol because of the larger dipole and therefore, stronger electrostatic forces. When an electronegative atom binds to the amine on PANI, by donating some electron density, the hole on the nitrogen is filled and the resistance on the polymer chain increases, which can be measured. ${ }^{[36]}$

(a)

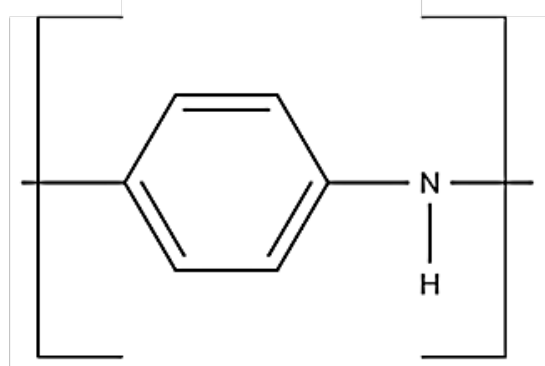

(b)

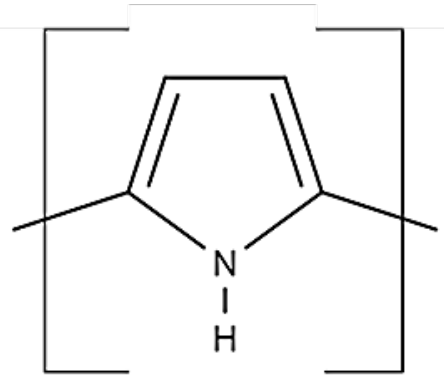

Figure 3. (a) Polyaniline (PANI) and (b) Polypyrrole (PPy).

By modifying PANI, the sensitivity and/or selectivity can be improved. Athawale and Kulkarni compared how different PANI derivatives responded to different aliphatic alcohols and found that selectivity was overall improved towards methanol when an ethyl group was added to the amine group. ${ }^{[40]}$ This ethyl group "protected" the nitrogen from the larger alcohols through steric hindrance, since an ethyl group is much larger than a single hydrogen atom. Due to methanol's smaller size, methanol is able to more easily reach the nitrogen, despite the added steric hindrance from the ethyl group. 
Polypyrrole (PPy) is very similar to PANI (see Figure 3b), containing a conjugated chain and an amine group. The conjugated chain allows electrons to migrate down the PPy chain and is thus, conductive, making it a common sensing material in resistive type sensors. ${ }^{[39,40]}$ PPy attracts alcohols through electrostatic forces with its amine group (slightly positively charged hydrogen on a nitrogen). The amine is able to hydrogen bond with the $-\mathrm{OH}$ in the alcohol. ${ }^{[43]}$ Because the amine is a secondary amine in nature (it is bonded to two carbon atoms, and one hydrogen atom), there is some steric hindrance surrounding the positively charged nitrogen. Due to the rigid nature of PPy, the chains are able to pack more closely together, creating smaller interstitial spaces for the analytes to diffuse into. ${ }^{[4]}$ The combination of the polar amine (-NH) on PPy, which is more attracted to other, more polar species that are able to hydrogen bond (such as small alcohols), with the steric hindrance that repulses larger molecules than methanol, explains the selectivity shown by Mabrook et al. ${ }^{[42]}$ Similarly, Babaei and Alizadeh demonstrated better selectivity by using perchlorate as a dopant. ${ }^{[41]}$ The perchlorate is negatively charged and thus attracted to the positively charged hydrogen on the amine group. By binding to the amine, the perchlorate "protected" some of the amines, thus reducing the number of available sensing sites (amine groups, in this case) for the analytes to bond to. Since perchlorate was only used as a dopant, not every amine would be protected.

Table 5 summarizes various polymeric sensing materials used for either methanol or ethanol. Selectivity values towards the target analyte are also shown in Table 5. The higher the value for the selectivity, the lower the response from the interferent. Typical interferents were other alcohols (e.g. methanol, ethanol, and propanol) and aromatics (e.g. benzene and toluene), amongst others.

Table 5. Polymeric Sensing Materials for Alcohols

\begin{tabular}{|c|c|c|c|c|c|}
\hline Analyte & $\begin{array}{l}\text { Sensing } \\
\text { Material }\end{array}$ & Dopant & $\begin{array}{l}\text { Detection } \\
\text { Limit }\end{array}$ & Selectivity & Reference \\
\hline Methanol & $\begin{array}{c}\text { Poly ( } N \text {-ethyl } \\
\text { aniline) } \\
\text { PNEA }\end{array}$ & $\mathrm{HCl}$ & & $\begin{array}{c}\text { Propanol (1.48) } \\
\text { Ethanol (1.86) } \\
\text { Butanol (2.88) } \\
\text { Heptanol (18.40) }\end{array}$ & [40] \\
\hline Methanol & $\begin{array}{c}\text { Polyaniline } \\
\text { (PANI) }\end{array}$ & $\mathrm{Pd}$ & $1 \mathrm{ppm}$ & - & [36] \\
\hline Methanol & $\begin{array}{c}\text { Polypyrrole } \\
\text { (РPy) }\end{array}$ & $\begin{array}{c}\text { Perchlorate } \\
\left(\mathrm{ClO}_{4}\right)\end{array}$ & 300 ppm & $\begin{array}{c}\text { Nitromethane (4.5) } \\
\text { Ethanol (4.9) } \\
\text { Acetonitrile (7.5) } \\
\text { Acetone (10.3) } \\
\text { 1-propanol (11.5) } \\
\text { Ethyl Acetate (12.5) }\end{array}$ & [41] \\
\hline
\end{tabular}




\begin{tabular}{|c|c|c|c|c|c|}
\hline & & & & $\begin{array}{c}\text { Chloroform (13) } \\
\text { 2-propanol (16.9) } \\
\text { Toluene (20.5) }\end{array}$ & \\
\hline Methanol & $\begin{array}{l}\text { Polyaniline } \\
\text { (PANI) }\end{array}$ & & 100 ppm & $\begin{array}{c}\text { Diimine } \\
\text { Triethylamine } \\
\text { Ethanol (1.3) }\end{array}$ & [37] \\
\hline Methanol & $\begin{array}{c}\text { Polypyrrole } \\
\text { (PPy) }\end{array}$ & None & 5000 ppm & $\begin{array}{c}\text { Propanol (1.6) } \\
\text { Chloroform (2.2) } \\
\text { Benzene (2.9) }\end{array}$ & {$[42]$} \\
\hline Ethanol & $\begin{array}{l}\text { Polyaniline } \\
\text { (PANI) }\end{array}$ & $\begin{array}{c}\text { Poly } \\
\text { (vinylidene } \\
\text { fluoride) } \\
\left(\mathrm{PVF}_{2}\right)\end{array}$ & 100 ppm & $\begin{array}{c}\text { Methanol (2.0) } \\
\text { Benzene (5.0) } \\
\text { Toluene (3.3) }\end{array}$ & [38] \\
\hline Ethanol & $\begin{array}{c}\text { Poly (2,5- } \\
\text { dimethyl } \\
\text { aniline) } \\
\text { (P25DMA) }\end{array}$ & None & 3 ppm & $\begin{array}{c}\text { Methanol (3.5) } \\
\text { Benzene (4.8) }\end{array}$ & [21] \\
\hline Ethanol & $\begin{array}{l}\text { Poly(diallyld } \\
\text { imethyl } \\
\text { ammonium } \\
\text { chloride) } \\
\text { (PDDAC) }\end{array}$ & $\begin{array}{l}\text { Tin Oxide } \\
\left(\mathrm{SnO}_{2}\right)\end{array}$ & 10 ppm & $\begin{array}{c}\text { Nitrogen dioxide } \\
\text { (19.6) } \\
\text { Hydrogen gas (9.9) } \\
\text { Sulfur dioxide (95.6) } \\
\text { Hydrogen Sulfide } \\
\text { (49.0) }\end{array}$ & [45] \\
\hline Ethanol & $\begin{array}{c}\text { Poly(3,4- } \\
\text { ethylenediox } \\
\text { ythiophene): } \\
\text { poly(styrene } \\
\text { sulfonate) } \\
\text { (PEDOT: } \\
\text { PSS) }\end{array}$ & None & 5000 ppm & - & [9] \\
\hline Ethanol & OV-275 & None & 500 ppm & $\begin{array}{l}\text { Benzene (7.1) } \\
\text { Methanol (8.8) }\end{array}$ & [46] \\
\hline
\end{tabular}

Poly (diallyldimethyl ammonium chloride) (PDDAC) (see Figure 4a) contains a positively charged nitrogen that acts as a Lewis acid. The oxygen on an alcohol, such as ethanol, has two lone pairs of electrons, capable of acting as a Lewis base. The electrostatic force draws the ethanol towards the PDDAC. Zhan et al. doped PDDAC with tin oxide $\left(\mathrm{SnO}_{2}\right)$, a common inorganic sensing material for volatile organic compounds (VOCs). ${ }^{[4]}$ By incorporating $\mathrm{SnO}_{2}$ into the PDDAC, the $\mathrm{SnO}_{2}$ nanoparticles were stabilized in the PDDAC matrix, and therefore aggregation of the nanoparticles was reduced, allowing for more $\mathrm{SnO}_{2}$ to be available to interact, 
through metal coordination, with the analytes. This resulted in the doped PDDAC being more sensitive to ethanol than either PDDAC or $\mathrm{SnO}_{2}$ alone. It should be noted that Zhan et al. claimed high selectivity towards ethanol by using inorganic gases as a comparison, which often behave differently than organic gases. ${ }^{[45]}$

(a)

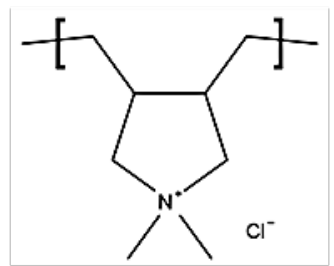

(b)

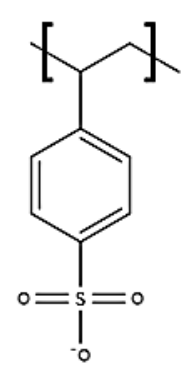

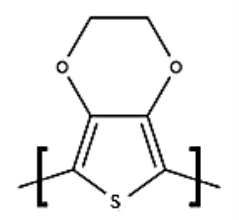

(c)

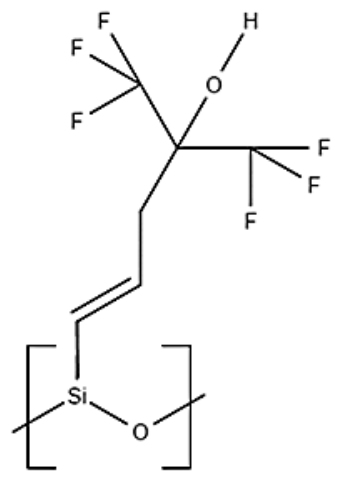

Figure 4. (a) Poly (diallyldimethyl ammonium chloride) (PDDAC), (b) Poly(3,4ethylenedioxythiophene): poly(styrene sulfonate) (PEDOT: PSS), (c) OV-275.

Poly(3,4-ethylenedioxythiophene): poly(styrene sulfonate) (PEDOT: PSS) (see Figure 4b) also is likely to interact with ethanol through Lewis acid-base interactions, with the sulfur and oxygen atoms on the PEDOT:PSS behaving as Lewis bases with their lone pairs of electrons. Ethanol, a Lewis acid, is able to hydrogen bond to the PEDOT:PSS. Similarly, the cyano groups on OV 275 (see Figure 4c) behave as Lewis acids and the ethanol is able to hydrogen bond to the nitrogen in the cyano group. In terms of selectivity, ethanol probably has a similar solubility to OV 275, compared to methanol, despite ethanol and methanol being chemically similar. The Hildebrand solubility parameters of ethanol and methanol are 26.6 and 29.7, respectively (see Table 2).

\section{Aldehydes and Ketones}

Aldehydes and ketones are very similar. Aldehydes have at least one double bonded oxygen $(\mathrm{C}=\mathrm{O})$ on a terminal carbon and ketones have at least one double bonded oxygen on a nonterminal carbon (see Figure 5). This oxygen draws electron density towards itself, resulting in a dipole with a slight negative charge on the oxygen, thus aldehydes and ketones are polar, but not as polar as alcohols. The two lone pairs on the oxygen act as a Lewis base, thus sensing materials that behave as Lewis acids are ideal. In addition, the high electronegativity of oxygen allows other molecules capable of hydrogen bonding to hydrogen bond to the oxygen in the aldehyde or ketone. 
(a)

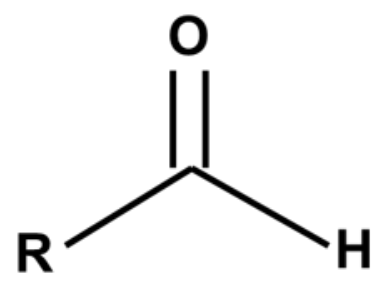

(b)

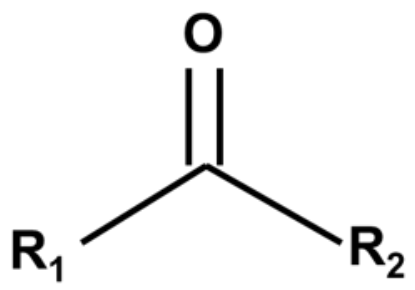

Figure 5. Schematic of an (a) aldehyde and a (b) ketone.

Due to the double bonded oxygen drawing electron density away from the carbon, both aldehydes and ketones are susceptible to nucleophilic attack from a nucleophile. In addition, the planar geometry of aldehydes and ketones limits steric hindrance; thus, the carbon is easily accessed by the nucleophile. However, ketones are more sterically hindered than aldehydes due to the fact that the ketone is surrounded by two carbon chains and an aldehyde has a hydrogen on one side. Nucleophilic attack is similar to Lewis acid-base interactions where the Lewis base (the nucleophile) donates electron density to the Lewis acid (electron deficient carbon) in the aldehyde or ketone. While Lewis acid-base interactions are likely to occur when hydrogen bonding is a possibility, it is more likely the dominant mechanism is hydrogen bonding due to the electrostatic forces. ${ }^{[4]}$

Formaldehyde is the simplest aldehyde, containing only one carbon. Many sensing materials have been investigated for formaldehyde due to its role in poor indoor air quality. ${ }^{[1]}$ It should be noted however, that many papers which describe sensing materials for formaldehyde use formalin (liquid formaldehyde) as their formaldehyde source. ${ }^{[47-50]}$ The problem is that formalin is $37 \%$ formaldehyde and $10-15 \%$ of stabilizer, typically methanol, in water. Therefore, it is difficult to assess whether the response is from formaldehyde or methanol, unless methanol is used as an interferent. If methanol shows a much poorer response than what was observed from formalin, then it can be assumed the response from the formalin is indeed from the formaldehyde. Otherwise, it is likely that response from the formalin is at least partially from both formaldehyde and methanol; however, it is impossible to distinguish which gas produces what percentage of the response. Therefore, the best method to evaluate a formaldehyde sensor is to use formaldehyde in gaseous form from a compressed gas cylinder rather than the vapour from formalin.

For example, for both polyaniline (PANI) doped with silver (Ag) nanoparticles ${ }^{[47]}$ and graphenepoly (methyl methacrylate) (graphene-PMMA) nanocomposite, ${ }^{[49]}$ the combination of methanol, formaldehyde and water is more likely to cause the response observed than formaldehyde alone. This is due to the ability of both methanol and water to hydrogen bond.

PANI is hydrophilic and both water and methanol are able to hydrogen bond to either the nitrogen or hydrogen in the amine; however, the hydrogen in PANI's amine is only able to 
hydrogen bond to formaldehyde. This effectively means that two molecules of methanol and/or water can bind to one amine (sensing site) on PANI (with one bound to the nitrogen and the other to the hydrogen) and only one formaldehyde molecule can bind to the amine. So for each sensing site (amine) on PANI, half as much formaldehyde is able to bond as its interferents, water and methanol. This results in a more sensitive sensor for the interferents than for formaldehyde. Additionally, this is why PANI is often used as a sensing material for methanol, as shown in Table 5.

Zhang et al. modified PANI by doping it with silver (Ag). ${ }^{[47]}$ The addition of Ag largely increased the porosity of the PANI matrix, which allowed more surface area, and therefore more sensing sites, for the analytes to bond to. The authors suggested nucleophilic attack as to why formaldehyde produced a larger response than the interferents tested; however, since formalin was used as the source for formaldehyde, this is not likely the case. Hydrogen bonding may be more likely between the amine group and the oxygen on formaldehyde, due to the electrostatic forces, since formaldehyde is polar $(2.33 \mathrm{D})$. This may also explain why there was such a large response to formaldehyde and methanol (which is capable of hydrogen bonding). In addition, acetone was tested as an interferent and a smaller response was observed for acetone than formaldehyde. This is despite the fact that acetone $(2.91 \mathrm{D})$ is more polar than formaldehyde (2.33 D), also behaves as a Lewis base (electrophile), and is susceptible to nucleophilic attack. However, Ag is often used to catalyze methanol into formaldehyde for industrial applications and thus, methanol and formaldehyde would be highly attracted to the Ag (more than acetone) and both are able to easily coordinate with the Ag, thus increasing the response observed for formalin. ${ }^{[51]}$

In some cases, the combination of methanol and formaldehyde can improve the sensitivity to formaldehyde. For example, Antwi-Boampong and BelBruno combined PANI and poly (ethylene imine) (PEI) (see Figure 6a) and doped it with formic acid to create a selective sensing material for formaldehyde. ${ }^{[4]}$ PANI, which is conductive, has increased resistance when an analyte sorbs onto it and thus was the responsive part of the sensing material. PEI was used to protect the PANI and improved its selectivity. The authors suggested a mechanism in which the PEI "trapped" the formaldehyde, which then was able to interact with PANI, resulting in a response. However, this does not explain the selectivity since PEI would "trap" many of the other interferents such as acetone, methanol, and ammonia, in a similar way to formaldehyde (acetone) or through hydrogen bonding (methanol and ammonia). A better explanation as to why formaldehyde produced such a large response, compared to the other interferents tested, is due to the way in which the materials were tested. The six interferents are all liquid at room temperature, whereas formaldehyde is not. Since formalin was used for formaldehyde, three vapours (formaldehyde, methanol, and water) were simultaneously exposed to the sensing material and thus, would result in all three gases interacting with the sensing material. Since methanol and water are able to hydrogen bond, they would more readily bind to the amine 
groups in PEI, reducing the number of available sorption sites on PEI. Formaldehyde would then not be able to bind to the PEI; however, it could bind to PANI, resulting in a large response since PANI's conductivity decreases as more analyte sorbs onto it.

(a)

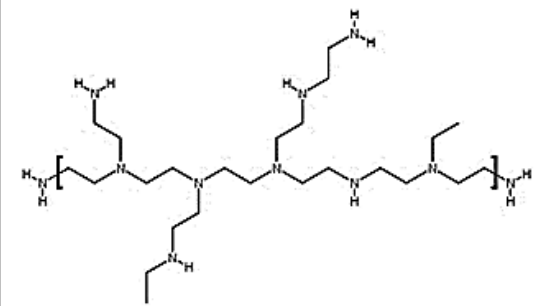

(b)

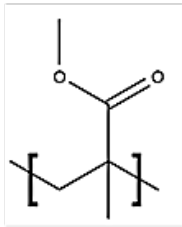

(c)

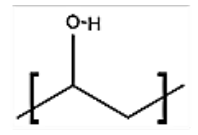

(d)

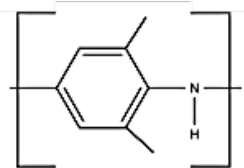

Figure 6. (a) Poly (ethylene imine) (PEI), (b) poly (methyl methacrylate) (PMMA), (c) poly (vinyl alcohol) (PVA), and (d) poly (2,5-dimethyl aniline) (P25DMA).

Similarly, Alizadeh and Soltani created a graphene-poly (methyl methacrylate) (graphenePMMA) nanocomposite that used the less hydrophilic nature of PMMA (see Figure 6b) to "protect" the graphene from highly polar analytes such as water. ${ }^{[49]}$ The PMMA sorbs interferents capable of hydrogen bonding, such as methanol and ethanol, and sterically repels larger interferents such as tetrahydrofuran and acetonitrile. Small molecules that cannot hydrogen bond, such as formaldehyde, are able to diffuse through the PMMA and sorb onto the alkoxy functional groups on graphene, reducing graphene's conductivity, and thus producing a response.

The morphology of the sensing material is also important. Wang et al. compared flat and nanofibrous membranes of poly (ethyleneimine)/poly (vinyl alcohol) (PEI/PVA) (see Figure 6c) as a sensing material for formaldehyde. ${ }^{[5]}$ It was found that the nanofibrous membrane was three times greater than the flat membrane. The nanofibers created a more porous membrane that allowed for easier diffusion into the matrix. This also resulted in a much higher specific surface area of the nanofibers than the flat membrane. A higher surface area results in more sensing sites available to the analytes and therefore, a potential for a larger response.

Wang et al. also compared different compositions of PEI/PVA and found that more than just morphology affected the sensing material's response. ${ }^{[5]}$ Two sensing materials were made with different PEI-PVA compositions that had similar specific surface area; however, the material with the higher PEI content produced a larger response. The authors suggest that PEI interacting with formaldehyde through Lewis acid-base interactions is the dominant sensing mechanism, with the formaldehyde acting as a Lewis base. However, both PEI and PVA are able to hydrogen bond to formaldehyde and thus, hydrogen bonding seems to be the dominant mechanism. In addition, the amines in PEI are stronger nucleophiles and Lewis bases and thus, if Lewis acid-base interactions did occur, it was more likely for formaldehyde to act as a Lewis acid. Further evidence for hydrogen bonding as the dominant mechanism exists when comparing 
ethanol and formaldehyde, which are of similar size. Ethanol is capable of hydrogen bonding, but formaldehyde is not; however, formaldehyde produced a much larger response. Steric interactions can explain why acetone, which is also susceptible to nucleophilic attack (acts as a Lewis acid), produces a much lower response than formaldehyde since formaldehyde is smaller than acetone. In addition, aldehydes are more reactive (stronger Lewis acids) than ketones.

Itoh et al. created a sensor able to detect aldehydes, with acetaldehyde producing a larger response than formaldehyde. ${ }^{[29]}$ The sensor used intercalated layers of poly (2,5-dimethyl aniline) (P25DMA) (see Figure 6d) and molybdenum trioxide $\left(\mathrm{MoO}_{3}\right)$. The $\mathrm{MoO}_{3}$ is used as a catalyst to oxidize alcohols into aldehydes and ketones. ${ }^{[52,53]}$ Therefore, alcohols, ketones, and aldehydes are all able to coordinate with Mo. The greater sensitivity to acetaldehyde and formaldehyde, than to ethanol, methanol, and acetone, suggests that the $\mathrm{MoO}_{3}$ was protected by the P25DMA and the analytes had to first diffuse through the P25DMA to reach the $\mathrm{MoO}_{3}$. The aromatic interferents would have much larger steric hindrance due to their larger size and bulkier configuration and thus, they did not readily diffuse into the P25DMA. In addition, the aromatic compounds may have bonded to the P25DMA through $\pi$-stacking with the aromatic rings in P25DMA; however, the change in resistance came from binding with the Mo, not the P25DMA.

Comparing the solubility parameters of P25DMA to these analytes (see Table 6), shows that P25DMA has a similar Hildebrand solubility parameter to acetaldehyde. The Hildebrand solubility parameter essentially amalgamates many of the different factors that affect solubility, thus giving a general rule for determining whether two compounds are miscible with one another. The Hansen solubility parameters are related to the Hildebrand solubility parameter (see Equation 7); they break down the solubility into three different contributions/parameters $\left(\delta_{\mathrm{D}}\right.$, $\delta_{\mathrm{H}}$, and $\delta_{\mathrm{P}}$, which correspond to the dispersion forces, hydrogen bonding, and polar intermolecular forces, respectively). If two compounds have similar solubility parameters, they are likely to be miscible with one another. Therefore, P25DMA is more soluble in acetaldehyde than the other eight interferents, and vice versa. This can be extended to diffusion, where more soluble analytes are able to more readily diffuse into the polymer matrix. Thus, acetaldehyde is more likely to diffuse into the P25DMA and be able to coordinate with the $\mathrm{MoO}_{3}$ creating a response from the resistive sensor. 
Table 6. Hildebrand and Hansen Solubility Parameters for P25DMA, PANI, and Gas Analytes

\begin{tabular}{ccccc}
\hline $\begin{array}{c}\text { Polymer/ } \\
\text { Analyte }\end{array}$ & $\boldsymbol{\delta} \mathbf{D}$ & $\begin{array}{c}\text { Hansen }\left(\mathbf{M P a}^{\mathbf{1 / 2}}\right)^{[28]} \\
\mathbf{\delta} \mathbf{H}\end{array}$ & $\boldsymbol{\delta} \mathbf{P}$ & $\begin{array}{c}\text { Hildebrand } \\
\left(\mathbf{M P a}^{\mathbf{1} / 2}\right)^{[28]}\end{array}$ \\
\hline P25DMA & - & - & - & $\mathbf{\delta}$ \\
PANI & $\mathbf{1 7 . 4}$ & $\mathbf{8 . 1}$ & $\mathbf{1 0 . 7}$ & $\mathbf{2 2 . 2} \mathbf{2}^{[30]}$ \\
Xylene & 17.8 & 1 & 3.1 & 18.0 \\
Toluene & 18 & 1.4 & 2 & 18.2 \\
Benzene & 18.4 & 0 & 2 & 18.6 \\
Chloroform & 17.8 & 3.1 & 5.5 & 19.0 \\
Acetone & 15.5 & 10.4 & 7 & 20.1 \\
Acetaldehyde & 14.7 & 8 & 11.3 & 21.1 \\
Formaldehyde & 12.8 & 14.4 & 15.4 & 24.7 \\
Ethanol & 15.8 & 8.8 & 19.4 & 26.6 \\
Methanol & 15.1 & 12.3 & 22.3 & 29.7 \\
\hline
\end{tabular}

Acetone is the simplest ketone. Acetone will interact with PANI in a similar manner to formaldehyde, although acetone is bulkier. When comparing the detection limits of acetone and formaldehyde in Table 7, note that PANI has been doped with various metal oxides or used in a copolymer, which would affect the response.

A blend of polypyrrole (PPy) and poly methyl methacrylate (PMMA) was also used as a sensing material for acetone. The amine group on PPy would behave similarly to the amine in PANI, hydrogen bonding to the double bonded oxygen in acetone. Ruangchuay et al. noted that while acetone reversibly bound to PPy, acetic acid (which was evaluated as an interferent) permanently bound to PPy. ${ }^{[54]}$ This is because PPy, which contains conjugated bonds (alternating double and single bonds), will partially oxidize in the presence of an anionic dopant such as $\alpha$-naphthalene sulfonate $\left(\alpha-\mathrm{NS}^{-}\right)$. This results in a positively charged nitrogen $(=\mathrm{N}-)$ on PPy that is able to stabilize the negatively charged dopant. When acetic acid is present, the $\alpha-\mathrm{NS}^{-}$steals a hydrogen from acetic acid, resulting in the acetic acid becoming its conjugate base (acetate), which then strongly binds to the positively charged PPy through electrostatic interactions (see Figure 7).

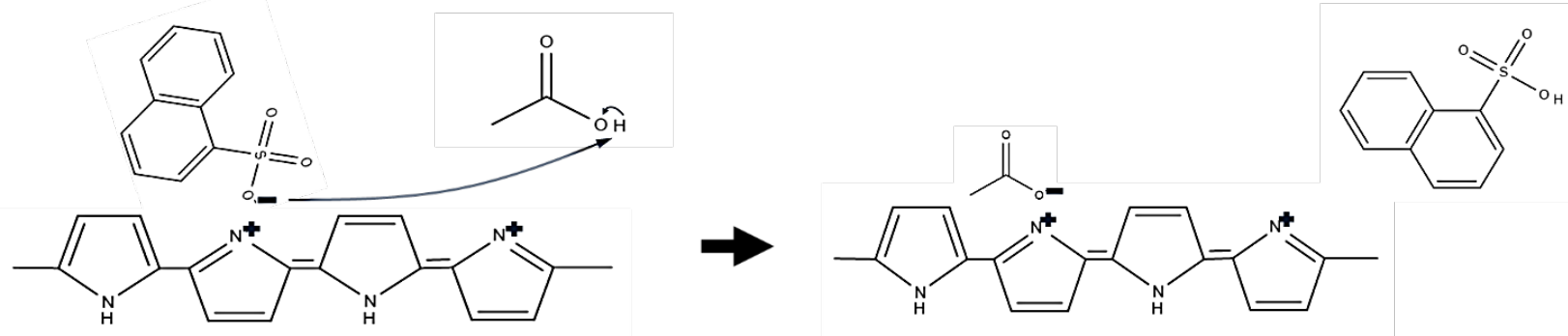

Figure 7. Substitution of $\alpha$-naphthalene sulfonate ( $\left.\alpha-\mathrm{NS}^{-}\right)$with acetic acid in polypyrrole (PPy). 
The addition of PMMA to PPy resulted in a polymer that swelled when analyte was present, which pushed the conductive PPy chains apart and reduced the conductivity of the sensing material. The greater the swelling of a polymer, the greater the resistance, and the larger the response observed. When acetone interacted with PPy/ $\alpha-\mathrm{NS}^{-} / \mathrm{PMMA}$, a lot of swelling occurred when acetone absorbed into the sensing material to hydrogen bond to PPy. However, when acetic acid absorbed into the sensing material, it displaced the $\alpha$-NS $\mathrm{N}^{-}$molecules by first neutralizing the $\alpha$-NS, and subsequently stabilizing the positively charged $=\mathrm{N}$ - in PPy. Therefore, the $\alpha$-NS would be free to migrate through the sensing material matrix to a spot where the $\alpha$-NS had more space (and was less sterically repulsed). This would result in less swelling of the PMMA, since acetic acid is smaller than $\alpha$-NS; however, the PMMA would not shrink since the $\alpha$-NS would still be in the polymer matrix. The difference in swelling results in a larger response to acetone than to acetic acid, thereby creating a sensor that is more selective towards acetone. $^{[54]}$

Table 7. Polymeric Sensing Materials for Aldehydes and Ketones

\begin{tabular}{|c|c|c|c|c|c|}
\hline Analyte & $\begin{array}{l}\text { Sensing } \\
\text { Material }\end{array}$ & Dopant & $\begin{array}{l}\text { Detection } \\
\text { Limit }\end{array}$ & Selectivity & Reference \\
\hline \multirow{5}{*}{$\begin{array}{l}\text { Form- } \\
\text { aldehyde }\end{array}$} & \multirow{5}{*}{$\begin{array}{c}\text { Polyaniline/ } \\
\text { Poly } \\
\text { (ethylene } \\
\text { imine) } \\
\text { (PANI/PEI) }\end{array}$} & \multirow{5}{*}{$\begin{array}{l}\text { Formic } \\
\text { Acid }\end{array}$} & & Chloroform (4068) & \multirow{5}{*}{ [48] } \\
\hline & & & & Acetone (2582) & \\
\hline & & & 38 ppm & $\begin{array}{c}\text { Dicholoromethane } \\
\text { (2469) } \\
\text { Water (186) }\end{array}$ & \\
\hline & & & & Methanol (121) & \\
\hline & & & & Ammonia (91) & \\
\hline $\begin{array}{l}\text { Form- } \\
\text { aldehyde }\end{array}$ & $\begin{array}{c}\text { Polyaniline } \\
\text { (PANI) }\end{array}$ & $\begin{array}{c}\mathrm{NiO} \\
(5 \text { wt. \%) } \\
\mathrm{Al}_{2} \mathrm{O}_{3} \\
\text { (wt.15\%) }\end{array}$ & $5 \mathrm{ppm}$ & $\begin{array}{c}\text { Acetaldehyde (1.79) } \\
\text { Benzene (2.11) } \\
\text { Ethanol (1.86) }\end{array}$ & {$[10]$} \\
\hline $\begin{array}{l}\text { Form- } \\
\text { aldehyde }\end{array}$ & $\begin{array}{l}\text { Polyaniline } \\
\text { (PANI) }\end{array}$ & $\begin{array}{c}\text { Ag } \\
(25 \text { mol \%) } \\
\text { Nitric acid }\end{array}$ & $1.24 \mathrm{ppm}$ & $\begin{array}{c}\text { Acetone (112) } \\
\text { Hexane (105) } \\
\text { Chloroform (25) } \\
\text { Benzene (3) }\end{array}$ & [55] \\
\hline
\end{tabular}




\begin{tabular}{|c|c|c|c|c|c|}
\hline $\begin{array}{l}\text { Form- } \\
\text { aldehyde }\end{array}$ & $\begin{array}{l}\text { Graphene- } \\
\text { Poly (methyl } \\
\text { methacrylate) } \\
\text { (Graphene- } \\
\text { PMMA) }\end{array}$ & None & $0.01 \mathrm{ppm}$ & $\begin{array}{c}\text { Dichloromethane } \\
\text { (27.4) } \\
\text { Acetone (11.4) } \\
\text { Water (11.4) } \\
\text { Acetonitrile (10.5) } \\
\text { Tetrahydrofuran (8.6) } \\
\text { Ethanol (6.9) } \\
\text { Methanol (6.2) }\end{array}$ & [49] \\
\hline $\begin{array}{l}\text { Form- } \\
\text { aldehyde }\end{array}$ & $\begin{array}{c}\text { Poly } \\
\text { (ethylene } \\
\text { imine) (PEI) }\end{array}$ & $\begin{array}{l}\text { Poly (vinyl } \\
\text { alcohol) } \\
\text { (PVA) } \\
\text { ( 40 wt.\%) }\end{array}$ & 10 ppm & $\begin{array}{c}\text { Ethanol (7.4) } \\
\text { Acetone (9.6) } \\
\text { Benzene (125) } \\
\text { Dicholoromethane } \\
\text { (125) } \\
\text { Toluene (125) } \\
\text { Chloroform (125) }\end{array}$ & {$[5]$} \\
\hline $\begin{array}{l}\text { Acet- } \\
\text { aldehyde }\end{array}$ & $\begin{array}{c}\text { Poly (2,5- } \\
\text { dimethyl } \\
\text { aniline)/ } \\
\text { Molybdenum } \\
\text { trioxide } \\
(\mathrm{P} 25 \mathrm{DMA} / \\
\left.\mathrm{MoO}_{3}\right)\end{array}$ & None & $0.91 \mathrm{ppm}$ & $\begin{array}{c}\text { Formaldehyde (1.3) } \\
\text { Chloroform (9.2) } \\
\text { Methanol (235) } \\
\text { Ethanol (235) } \\
\text { Acetone (47.1) } \\
\text { Benzene (235) } \\
\text { Toluene (42.8) } \\
\text { Xylene (118) }\end{array}$ & [29] \\
\hline Acetone & $\begin{array}{l}\text { Polyaniline } \\
\text { (PANI) }\end{array}$ & $\mathrm{HCl}$ & 29 ppm & - & [56] \\
\hline Acetone & $\begin{array}{c}\text { Polypyrrole/ } \\
\text { Poly (methyl } \\
\text { methacrylate) } \\
\text { (PPy/ } \\
\text { PMMA) }\end{array}$ & $\begin{array}{c}\alpha- \\
\text { naphthalene } \\
\text { sulfonate } \\
\left(\alpha-\mathrm{NS}^{-}\right) \\
(\sim 8 \%)\end{array}$ & $30.3 \%$ & Acetic Acid (3.9) & [54] \\
\hline
\end{tabular}

\section{Amines}

Despite the emphasis on how volatile organic compounds (VOCs) interact with polymeric sensing materials, ammonia has been included even though it is not a VOC. Ammonia has been included because it is essentially the simplest form of an amine group, where all R-groups are hydrogens.

Ammonia is a small, polar molecule capable of behaving as a Lewis base and able to hydrogen bond. Ammonia is electrostatically attracted to sensing materials that are also polar and able to 
hydrogen bond. This includes polymers that have polar functional groups, including amines such as polyaniline (PANI) ${ }^{[56,57]}$ and polypyrrole (PPy); ${ }^{[59]}$ carboxylic acids such as poly (acrylic acid) (PAA); ${ }^{[60]}$ and esters such as poly (methyl methacrylate) (PMMA). ${ }^{[61]}$

The amine groups in PANI and PPy are able to hydrogen bond to ammonia. Acid-doped PANI and PPy are both conductive and have better conductivity when the polymer chains are more crystalline, which results in closer stacking of the polymer chains. ${ }^{[62]}$ The small size of ammonia means it is less sterically hindered and thus, still able to diffuse into the smaller interstitial spaces of PANI and PPy. In addition, the acid doping results in positively charged amine groups (acid) on both polymers that attract the slightly negative nitrogen in ammonia (base), resulting in a Lewis acid-base interaction. ${ }^{[59]}$

Similarly, ammonia is able to hydrogen bond to the $\mathrm{OH}$ in the carboxylic acid on PAA; however, ammonia is also able to hydrogen bond to the double bonded oxygen as well. It should be noted that ammonia and carboxylic acids commonly undergo acid-base reactions, creating an amide, and therefore, ammonia can chemically bind to the PAA, making it extremely difficult to remove and thus reduce the reusability of the sensing material. This was observed by. ${ }^{[60]}$

Multiple sensors listed in Table 8 used titanium dioxide $\left(\mathrm{TiO}_{2}\right)$ nanoparticles to improve the sensitivity towards ammonia. $\mathrm{TiO}_{2}$ is commonly used to oxidize ammonia into nitrogen monoxide (NO) and nitrogen dioxide $\left(\mathrm{NO}_{2}\right){ }^{[63]}$ Therefore, ammonia will coordinate well with $\mathrm{TiO}_{2}$. In addition, $\mathrm{TiO}_{2}$ was able to coordinate well with both PAA and PANI. Gold (Au) nanoparticles were also used as a dopant in PANI; ${ }^{[58]}$ however, it was not likely that $\mathrm{Au}$ improved the sensitivity to ammonia. It is more likely that the mercaptans (which contain an $\mathrm{SO}_{3}{ }^{-}$) that stabilized the Au nanoparticles are what improved the response to ammonia, compared to undoped PANI. The negatively charged mercaptan electrostatically attracted the slightly positively charged hydrogens on ammonia.

Triethylamine (TEA) contains three ethyl $\left(\mathrm{C}_{2} \mathrm{H}_{5}\right)$ groups instead of three hydrogen atoms around a nitrogen atom. TEA is therefore much bulkier than ammonia, and it is also less polar than ammonia. In both cases, the nitrogen carries a slight negative charge; however, TEA is unable to hydrogen bond unless it bonds to something capable of hydrogen bonding like an amine or alcohol. Ji et al. used a copolymer of PANI-PMMA doped with toluene sulfonic acid (TSA). ${ }^{[64]}$ The TSA protonated the amine on PANI and also provided some steric hindrance (since TSA is a bulky acid), increasing the interstitial spaces between the polymer chains, thus making the amines on PANI more accessible. The slightly negatively charged nitrogen in TEA was attracted to the positively charged amine on PANI.

Note that doping a sensing material may improve non-sensing properties, such as mechanical or electrical, and thus, doping may not always be beneficial in terms of sensitivity and selectivity. 
The addition of poly (vinyl alcohol) (PVA) to PPy was to improve the mechanical properties of PPy ${ }^{[59]}$ While the PVA likely increased the interstitial spaces in the polymeric material, thereby improving diffusion into the polymer, the alcohol groups on PVA were also able to hydrogen bond to ammonia. This would have reduced the sensor's sensitivity, since sorption onto PPy is what created a change in conductivity (in this case) and thus, a measurable response. Any ammonia bound to PVA would not have produced a measureable response.

Table 8. Polymeric Sensing Materials for Amines

\begin{tabular}{|c|c|c|c|c|c|}
\hline Analyte & $\begin{array}{c}\text { Sensing } \\
\text { Material }\end{array}$ & Dopant & $\begin{array}{l}\text { Detection } \\
\text { Limit }\end{array}$ & Selectivity & Reference \\
\hline Ammonia & $\begin{array}{l}\text { Poly (methyl } \\
\text { methacrylate)- } \\
\text { Polyaniline } \\
\text { (PMMA- } \\
\text { PANI) }\end{array}$ & $\begin{array}{l}\text { bis(2-ethyl } \\
\text { hexyl) } \\
\text { hydrogen } \\
\text { phosphate } \\
\text { (DiOHP) }\end{array}$ & $10 \mathrm{ppm}$ & - & [61] \\
\hline Ammonia & $\begin{array}{c}\text { Titanium } \\
\text { dioxide/ } \\
\text { poly(acrylic } \\
\text { acid) } \\
\left(\mathrm{TiO}_{2} / \mathrm{PAA}\right)\end{array}$ & None & $0.11 \mathrm{ppm}$ & $\begin{array}{c}\text { Butyl amine (1.9) } \\
\text { Pyridine (3.8) } \\
\text { Ethanol (13.8) } \\
\text { Toluene (20.4) } \\
\text { Chloroform (43.6) }\end{array}$ & [60] \\
\hline Ammonia & $\begin{array}{c}\text { Titanium } \\
\text { dioxide }\left(\mathrm{TiO}_{2}\right)\end{array}$ & $\begin{array}{l}\text { Polyaniline } \\
\text { (PANI) } \\
\text { Hydro- } \\
\text { chloric } \\
\text { Acid (HCl) }\end{array}$ & $50 \mathrm{ppt}^{*}$ & - & [57] \\
\hline Ammonia & $\begin{array}{l}\text { Polypyrrole } \\
\text { (PРy) }\end{array}$ & $\begin{array}{c}\text { Poly (vinyl } \\
\text { alcohol) } \\
\text { PVA } \\
\text { (5 w/v\%) }\end{array}$ & $1000 \mathrm{ppm}$ & - & [59] \\
\hline Ammonia & $\begin{array}{l}\text { Polyaniline } \\
\text { (PANI) }\end{array}$ & $\begin{array}{c}\text { Gold (Au) } \\
\text { 3- } \\
\text { mercapto- } \\
\text { 1-propane } \\
\text { sulfonic } \\
\text { acid } \\
\text { (3MPS) }\end{array}$ & 10.8 ppm & $\begin{array}{c}\text { Ethanol } \\
\text { Toluene } \\
\text { Acetonitrile }\end{array}$ & [58] \\
\hline
\end{tabular}




\begin{tabular}{cccccc}
\hline $\begin{array}{c}\text { Triethyl- } \\
\text { amine }\end{array}$ & $\begin{array}{c}\text { PMMA/ } \\
\text { PANI }\end{array}$ & $\begin{array}{c}\text { Toluene } \\
\text { sulfonic } \\
\text { acid (TSA) }\end{array}$ & $20 \mathrm{ppm}$ & - & [64] \\
\hline
\end{tabular}

*parts per trillion (ppt)

\section{Aromatics}

Aromatics are molecules that contain conjugated (alternating single and double bonds) planar rings. The alternating single and double bonds, combined with the planar geometry, result in delocalized electron density across the p-orbitals in the aromatic ring. Filled p-orbitals that are oriented such that the delocalization is in a planar geometry allow for $\pi$-stacking and therefore, aromatics are attracted to other aromatics. There are cases where an aromatic can $\pi$-stack with other functional groups such as a trifluoro-group (as in SXFA, see Figure 8), where the p-orbitals of the three fluorine atoms are in a planar configuration and benzene, which is also planar, is able to $\pi$-stack. ${ }^{[65]}$

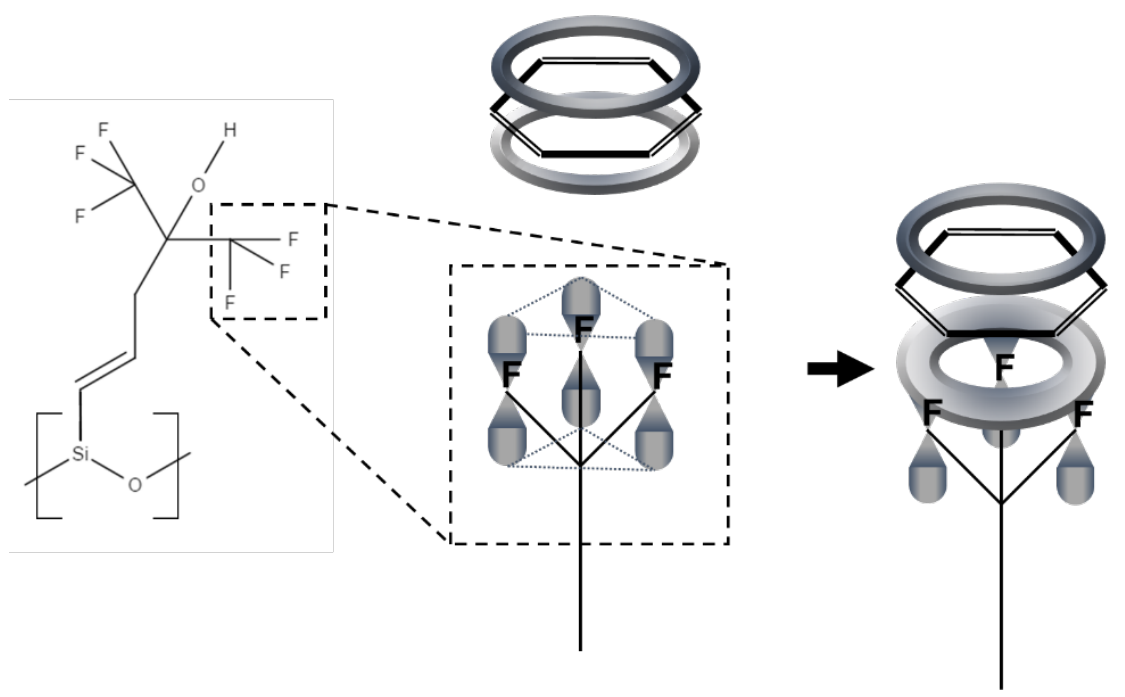

Figure 8. Benzene $\pi$-stacking onto SXFA.

All of the polymeric materials used for aromatic analyte detection are at least partly conjugated and thus, have an aromatic component to them. This is what the aromatic rings in benzene, toluene, and xylene are able to $\pi$-stack with. Because aromatic compounds are typically the only VOCs that are able to $\pi$-stack, many non-aromatic interferents will not bind very well and thus high selectivity will be observed towards the aromatic compounds. ${ }^{[66]}$ Aromatic molecules are also bulkier than the other VOCs discussed and therefore, need larger interstitial spaces to easily diffuse into the polymer matrix.

For example, as shown in Figure 9a, a copolymer (poly (methyl methacrylate-co-chloromethyl styrene) modified with $N, N$-dimethyl-1,3-propanediamine (MCD)) contains multiple aromatic 
rings and other long R-chains that create large interstitial spaces between the polymer chains. These larger interstitial spaces allow toluene to diffuse into MCD more easily and bind to the aromatic rings through $\pi$-stacking, which pulls charge density away from the conductive MCD. This effectively makes it harder for the charge to travel along the copolymer chains, which results in a reduction of MCD's conductivity. ${ }^{[67]}$ Note that this displacement of charge density while the polymer and aromatic analytes interact through $\pi$-stacking results in a change in conductivity. This is how most of the responses are measured for the sensors listed in Table 9. Resistive-type sensors are commonly used for aromatic analytes because a conjugated polymer is typically conductive. ${ }^{[68]}$
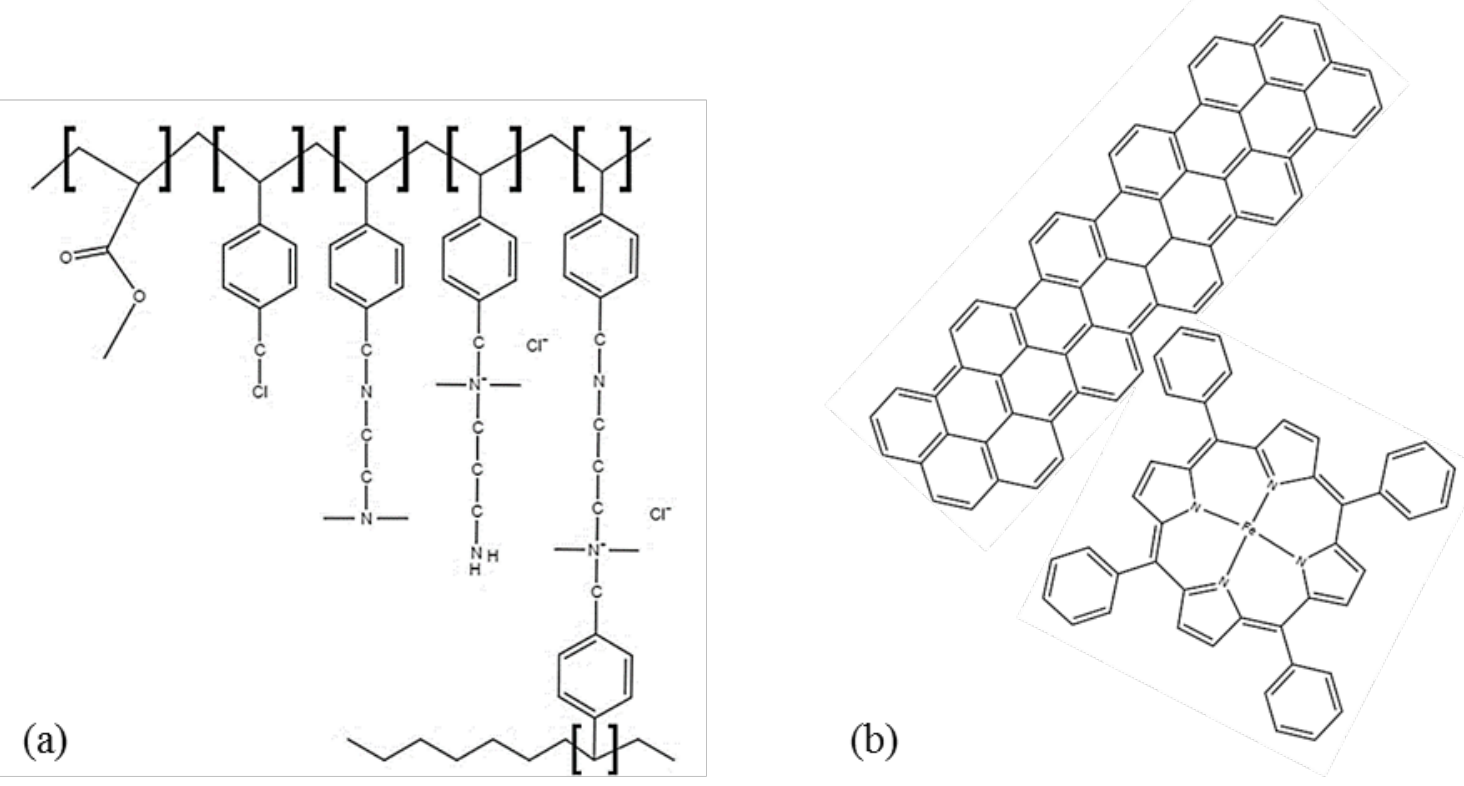

Figure 9. (a) MCD and (b) single wall carbon nanotubes doped with iron-tetraphenylporphyrin (SWCNT-Fe-TPP).

Toluene has one methyl functional group and thus, has a small dipole moment (0.36 D). However, it is below $0.4 \mathrm{D}$ and therefore, toluene is still considered non-polar. Xylene, on the other hand, is considered polar with a dipole moment of $0.64 \mathrm{D}$. This is why polymers, such as polyaniline (PANI) and polypyrrole (PPy), are slightly more selective towards xylene than toluene and benzene. The electrostatic forces are why xylene is favoured over toluene and benzene when interacting with $\mathrm{PANI}^{[69]}$ and PPy. ${ }^{[70]}$ Note that while ethylbenzene is also polar $(0.58 \mathrm{D})$, it is slightly less polar than xylene; ethylbenzene is also bulkier, which means ethyl benzene is also more sterically hindered than xylene.

Rushi et al. did, however, demonstrate that single wall carbon nanotubes doped with irontetraphenylporphyrin (SWCNT-Fe-TPP) (see Figure 9b) had slightly better selectivity towards toluene than xylene, despite all three aromatic compounds (benzene, toluene, and xylene) being 
able to $\pi$-stack with the aromatic rings on both the porphyrin and SWCNT. ${ }^{[71]}$ This is due to the incorporation of Fe. Toluene coordinates well with Fe and thus, is more preferentially bound than xylene and benzene. ${ }^{[72]}$

Table 9. Polymeric Sensing Materials for Aromatics

\begin{tabular}{|c|c|c|c|c|c|}
\hline Analyte & $\begin{array}{c}\text { Sensing } \\
\text { Material }\end{array}$ & Dopant & $\begin{array}{c}\text { Detection } \\
\text { Limit }\end{array}$ & Selectivity & Reference \\
\hline Benzene & SXFA & None & 500 ppm & $\begin{array}{l}\text { Ethanol (11.3) } \\
\text { Methanol (12.5) }\end{array}$ & [63] \\
\hline Toluene & $\begin{array}{l}\text { MMA-CMSt- } \\
\text { DMPDA }\end{array}$ & $\begin{array}{c}\text { Carbon } \\
\text { Black } \\
(\sim 10 \%)\end{array}$ & 50 ppm & - & [67] \\
\hline Toluene & $\begin{array}{l}\text { Single wall } \\
\text { carbon } \\
\text { nanotubes } \\
\text { (SWNT) }\end{array}$ & $\begin{array}{c}\text { Iron- } \\
\text { tetraphenyl } \\
\text { porphyrin } \\
\text { (Fe-TPP) }\end{array}$ & $500 \mathrm{ppb}$ & $\begin{array}{c}\text { Xylene (1.8) } \\
\text { Benzene (2.8) }\end{array}$ & [71] \\
\hline Toluene & P3HT-benzyl & & $1 \mathrm{ppm}$ & $\begin{array}{c}\text { Methanol (6.1) } \\
\text { Ethanol }(>4000) \\
\text { Isopropanol }(>4000) \\
\text { Acetone }(>4000) \\
\text { Methylene Chloride } \\
\text { (4.6) } \\
\text { Acetonitrile (6.8) } \\
\text { Benzene }(2.1) \\
\text { Hexane }(>4000) \\
\text { Cyclohexane }(>4000)\end{array}$ & [66] \\
\hline Xylene & Polyaniline & $\mathrm{HCl}$ & 200 ppm & $\begin{array}{l}\text { Toluene (1.3) } \\
\text { Benzene (1.9) }\end{array}$ & [69] \\
\hline Xylene & Polypyrrole & $\mathrm{Cl}^{-}$ & $67 \mathrm{ppm}$ & $\begin{array}{c}\text { Ethylbenzene (2) } \\
\text { Toluene (4) } \\
\text { Benzene (10) }\end{array}$ & [70] \\
\hline
\end{tabular}

\section{Alkanes}

Unlike most of the volatile organic compounds (VOCs) discussed, alkanes are non-polar. Therefore, alkanes are not attracted to sensing materials through large electrostatic forces from dipoles. Instead, alkanes are attracted by very small van der Waals forces, which only occur at very short distances. 
Alkanes are simple hydrocarbons that only have singly bonded carbons and hydrogens. They can be either linear or branched; branched alkanes are bulkier and thus more sterically hindered. As an example, methane, the simplest hydrocarbon and alkane is discussed.

Methane is a small, non-polar molecule which is typically detected through the catalytic oxidation over metal and metal oxide catalysts. ${ }^{[73]}$ In some cases, a polymer matrix is used to support the catalytic metal oxide (see Table 10). For example, Xie et al. used a polyaniline (PANI) doped with camphor sulfonic acid as a matrix for palladium oxide (PdO). ${ }^{[7]}$ PdO is used as a catalyst to oxidize methane and thus, readily coordinates with methane. It is important that these materials have a porous structure that allows methane to diffuse through the polymer and reach the metal oxide, as is the case for the PANI-PdO nanocomposite. The PANI matrix was used to "filter" out interferents such as water (humidity), since PANI is hydrophilic and water is able to hydrogen bond to the amines in PANI. The removal of water as an interferent is important, since water reduces PdO's effectiveness as a catalyst for methane. ${ }^{[75]}$

Supramolecular cryptophane-A, which is a cage-like structure (see Figure 10), has also been used as a sensing material for methane. ${ }^{[76,77]}$ Cryptophane-A has a shell-like structure and is able to form a stable complex with methane. ${ }^{[78]}$ Methane's small size means it is not easily sterically hindered and can thus enter the cryptophane-A, since it is not being electrostatically repelled. This lack of repulsion is also due to methane's non-polar nature. The complex formed between methane and cryptophane-A is a result of van der Waals forces. ${ }^{[77]}$

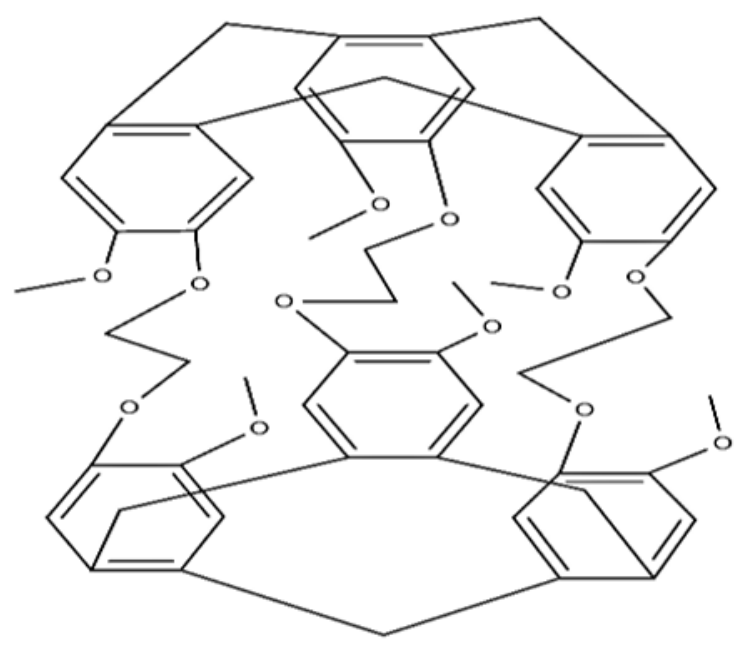

Figure 10. Schematic of Cryptophane-A. 
Table 10. Polymeric Sensing Materials for Alkanes

\begin{tabular}{|c|c|c|c|c|c|}
\hline Analyte & $\begin{array}{c}\text { Sensing } \\
\text { Material }\end{array}$ & Dopant & $\begin{array}{c}\text { Detection } \\
\text { Limit }\end{array}$ & Selectivity & Reference \\
\hline Methane & $\begin{array}{l}\text { Polyaniline } \\
\text { (PANI) }\end{array}$ & $\begin{array}{c}\text { PdO (17\%) } \\
\text { Camphor } \\
\text { sulfonic } \\
\text { acid (CSA) }\end{array}$ & 3000 ppm & - & [74] \\
\hline Methane & $\begin{array}{c}\text { Crytophane- } \\
\text { A }\end{array}$ & None & 5000 ppm & - & [76] \\
\hline Methane & $\begin{array}{c}\text { Crytophane- } \\
\text { A }\end{array}$ & None & $\begin{array}{c}20000 \\
\text { ppm }\end{array}$ & $\begin{array}{c}\text { Ammonia } \\
\text { (1.4) } \\
\text { Nitrogen Dioxide } \\
\text { (3.2) } \\
\text { Carbon Monoxide } \\
\text { (51.5) } \\
\text { Hydrogen Gas } \\
(9.4)\end{array}$ & [77] \\
\hline
\end{tabular}

\section{Experimental}

We now combine examples from the literature as well as our own experimental work to evaluate potential sensing materials for different analytes. The following experimental procedures were used to synthesize and evaluate sensing materials.

\section{Polymer Synthesis}

This procedure is for the polymeric materials that were synthesized using their respective monomers. Some polymers were bought directly from the manufacturer and are labelled as such in Section 5, whereas the polymers that were synthesized are designated by their respective monomers. All chemicals were used as received from the manufacturer.

The monomer (up to $0.4 \mathrm{~g}$ ), metal oxide nanoparticle dopant (up to $0.08 \mathrm{~g}$ ), and deionized water $(20 \mathrm{~mL})$ were added to a $100 \mathrm{~mL}$ round bottom flask. The total mass of the monomer and the metal oxide dopant was $0.4 \mathrm{~g}$; therefore, if $0.08 \mathrm{~g}$ of dopant was added, $0.32 \mathrm{~g}$ of monomer was used; no dopant was added to $0.4 \mathrm{~g}$ of monomer. The monomer, dopant (if added), and water were sonicated for 30 minutes. Then the mixture was cooled to $-1{ }^{\circ} \mathrm{C}$. In each polymerization, $1.0 \mathrm{~g}$ of ammonium persulfate (reagent grade, Sigma-Aldrich, Oakville, Ontario, Canada) was used as the initiator. The initiator was dissolved in $5 \mathrm{~mL}$ of deionized water, then immediately added to the cooled monomer mixture. The flask was swirled for 30 seconds, and the mixture 
left to polymerize for 6 hours. The polymer was filtered using a Büchner funnel and Whatman \#5 filter paper. The polymer was washed with deionized water and ethanol, and then left to air dry. The polymers were stored in $20 \mathrm{~mL}$ scintillation vials at room temperature $\left(21^{\circ} \mathrm{C}\right) .^{[21]}$ Note that all of the chemicals were used as received from the manufacturer and no purification was done prior to the polymerizations.

\section{Test System}

The polymeric sensing materials were evaluated on a specially designed test system. The polymeric sensing materials were exposed to low concentrations of different analytes, in a balance of nitrogen, to determine the amount of each analyte that sorbed onto the polymer.

Gas analytes flowed from gas cylinders (certified standard grade, Praxair, California, USA) into the test system using a mass flow controller (MKS RS-485) at a flow rate of $200 \mathrm{sccm}$. The gas entered a $100 \mathrm{~mL}$ round bottom flask, where the polymer sample was deposited. A pressure controller (MKS 640A) and flow meter (MKS 179A) placed after the round bottom flask were used to ensure that the flow rate and pressure were maintained in the system (i.e. the test system was not leaking). The gas then flowed into a very sensitive gas chromatograph (GC) that was used to measure the amount of gas analyte that did not sorb onto the polymeric sensing material (see Figure 11). The GC (Varian 450) had a pulse discharge helium ionization detector (PDHID) that was able to measure down to the parts per billion (ppb) range. ${ }^{[79]}$

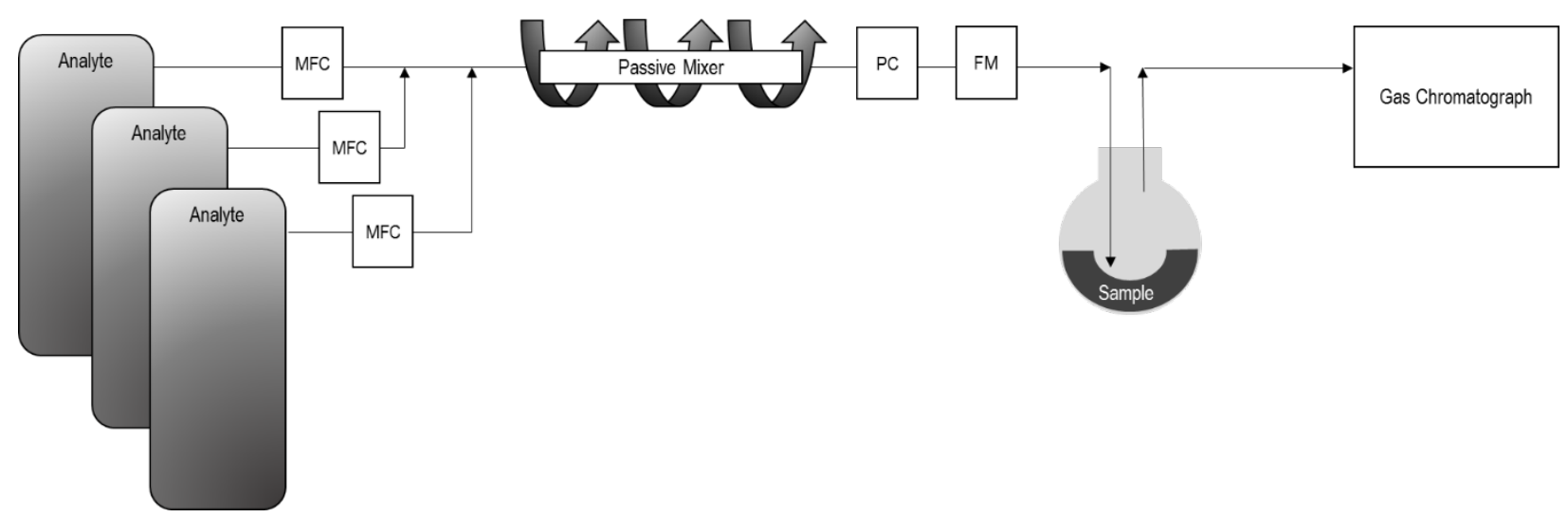

Figure 11. Schematic of the test system, where MFC, PC, and FM are mass flow controller, pressure controller, and flow meter, respectively. For example, the three analyte tanks could be ethanol, methanol, and benzene.

\section{Evaluation of Polymeric Materials}

The polymer samples were prepared by depositing $0.120 \mathrm{~g}$ of polymer sample into a $100 \mathrm{~mL}$ round bottom flask with $20 \mathrm{~mL}$ of ethanol. The polymer was swirled around the flask to evenly distribute the polymer. The flask was then placed in an oven at $50{ }^{\circ} \mathrm{C}$ for 16 hours to allow the 
ethanol to evaporate. The polymer samples were then cooled to room temperature $\left(21^{\circ} \mathrm{C}\right)$ before evaluation on the test system was done. The polymer samples were purged with 5.0 grade nitrogen (Praxair, Mississauga, Ontario, Canada) for 75 minutes just prior to being tested on the system.

An empty flask (blank) was run on the test system initially to ensure that the appropriate concentration of analyte was present. For example, if $5 \mathrm{ppm}$ of ethanol was being used to evaluate a polymer, the GC should measure $5 \mathrm{ppm}$ of ethanol in the gas stream since there was no polymer in the blank and thus, nothing for the ethanol to sorb onto. Note that each gas analyte was not diluted further and the polymeric materials were evaluated using the certified standard concentrations.

Each sample (both the polymers and the blank) was subjected to the gas analyte for 60 minutes, after which two consecutive samples of the gas were measured by the GC. This was done to ensure the sorption had reached equilibrium. The amount of gas analyte measured by the GC was the amount of analyte that did not sorb onto the polymer sample. By subtracting the amount not sorbed from the amount of analyte (concentration) from the gas tank, the amount of analyte sorbed onto the polymer was obtained.

Three independent replicate samples were run for each polymer-gas pair evaluated. The amount of gas sorbed was used to compare the effectiveness of different polymeric sensing materials for a single analyte and/or to compare the sorption of multiple analytes on a single polymer sample (i.e. selectivity). The results were statistically analyzed using analysis of variance (ANOVA), Bonferroni t-test, and Fisher's least significant difference (LSD) to determine if there were significantly different responses from different polymer and gas analyte combinations.

\section{Selecting Sensing Materials}

When designing or selecting sensing materials for gas analytes, there are a few items to be considered. The first step is to choose a target analyte (volatile organic compound, VOC) for a specific application. Then, examining the chemical nature of the target analyte, determine which functional group(s) are present on the analyte. These functional groups will dictate the dominant sensing mechanisms with which the sensing material and analyte will interact.

Before continuing with sensing material selection, it is important to look at the type of sensor that will be used since the type of sensor may constrain the types of polymers used. For example, a resistive type sensor requires a conductive polymer and a capacitive sensor may require a polymer that is capable of swelling. If the type of sensor is unknown, then the issue becomes more complicated, but still a sensing material could be chosen that is able to work on a variety of different types of sensors. 
In addition, the environment the sensor will be used in may also provide constraints. These include the types of interferents present which have an effect on selectivity, operational temperatures, size of sensor, response and recovery times. It is important to consider all these factors when selecting potential sensing materials.

\section{Sensor Application Requirements}

A sensor's application will always carry some constraints such as operational temperature and sensitivity required. It is important to consider these constraints when designing a sensing material. The sensor application designates not only the target analyte, but also the environment in which the sensor will be used.

\section{Sensitivity}

The sensor application determines how sensitive the sensor needs to be. For example, a formaldehyde sensor for indoor air quality must be able to detect formaldehyde below the concentration that has been determined as toxic. According to the World Health Organization (WHO), the concentration of formaldehyde should not exceed $0.08 \mathrm{ppm}$ (80 ppb) over a 30 minute exposure. ${ }^{[1]}$ Therefore, a formaldehyde sensor for indoor air quality must be able to at least detect $0.08 \mathrm{ppm}$ of formaldehyde (the target detection limit). Ideally, a sensor's sensitivity should be lower than the target detection limit.

To achieve such high sensitivity (low detection limit), the sensing material must have as many sensing sites as possible. This is because there is a correlation between the amount of analyte that sorbs and the sensitivity; the more the analyte sorbs, the more sensitive the sensing material. In addition, when less analyte is present (i.e. lower concentration), less analyte sorbs onto the sensing material. Therefore, having more sensing sites available is likely to increase the number of analyte molecules that sorb (barring steric hindrance and other counterbalancing sensing mechanisms), thereby increasing the sensitivity of the sensing material.

Furthermore, the sensitivity of the sensor should not be limited by the sensor electronics. The noise should be at least three times lower than the response of the sensor to the target analyte at the detection limit. The sensitivity of the sensor must be evaluated with the sensing material on the sensor, since some sensing materials work better (have better sensitivity) than other materials on the same sensor. Also, two different sensing materials may produce different noise levels (one material may produce more noise than the other) on the same sensor. ${ }^{[21]}$ 


\section{Selectivity}

In any given environment, there will be the target analyte, as well as other interferents present. The application, and thus the environment the sensor will be used in, determines what these interferents are. For example, in an indoor air quality sensor, where the target analyte is formaldehyde, common interferents include acetone, ammonia, butanol, formic acid, toluene, and xylene. ${ }^{[80]}$ Therefore, a selective sensor for formaldehyde must selectively identify formaldehyde when all of these other VOCs are present.

It is important to note that the concentrations of all VOCs present in an environment are not equal. Some interferents may be at concentrations an order of magnitude lower than the target analyte's concentration. If this is the case, the interferents present in the environment at very low concentrations (i.e. present at the ppb level when the concentration of the target analyte is at the ppm level) can be ignored (considered negligible), since they are not likely to create a response from the sensor at such low concentrations. ${ }^{[80]}$

\section{Operational Temperature}

The operational temperature is an important consideration, especially with regards to polymeric materials. It is important that the polymeric sensing materials are in their glassy states, since polymers above their glass transition temperature $\left(\mathrm{T}_{\mathrm{g}}\right)$ begin to soften and "flow". If this occurs while a sensor is in operation, a response may not be detectable or the softened polymer chains may produce an erroneous or biased response. Because of this, the $\mathrm{T}_{\mathrm{g}}$ of a potential sensing material should be above (ideally, well above) the operational temperature. Therefore, the operational temperature may eliminate some potential polymeric sensing materials. The operational temperature may also be optimized to improve the selectivity of the sensor. ${ }^{[81]}$

In addition to the temperature at which the analyte is being sensed, the temperature at which the sensor recovery takes place may also be a consideration. This is the case for sensors with builtin heaters that are used to speed up the recovery times of a sensor by providing more energy (heat) to break the bond between the analyte and sensing material, regenerating the sensing material. $^{[19]}$ Therefore, the $T_{g}$ of potential polymeric sensing materials must be above the temperature at which the sensor is heated, not just the sensing temperature.

\section{Response and Recovery Times}

Most applications require fast response and recovery times, ideally in the order of seconds or quicker. The response time is the time needed to reach $90 \%$ of the final signal (100\% response); recovery time is the time the response takes to return to the baseline. Generally, the recovery time is longer than the response time. 
It is possible to reduce the response time by doping a polymeric material with a metal oxide dopant, especially in conductive sensors. For example, the incorporation of platinum (Pt) into polyaniline (PANI) increases the conversion rate between conductor and insulator, which decreases both the response and recovery times. ${ }^{[82]}$ The recovery time can also be reduced by heating the sensing layer, which gives energy to the analyte molecules and breaks the physical bonds formed between the analyte and sensing material. ${ }^{[3]}$

\section{Target Analyte's Chemistry (Mechanisms)}

When choosing sensing materials for a target analyte, it is important to look at the functional groups of the target analyte. For example, ethanol has an alcohol, formaldehyde has an aldehyde, and benzene is aromatic. The functional groups dictate the chemistry with which the analyte will interact with the polymeric sensing materials. Therefore, the functional groups on the polymeric materials are also important. Section 3 described the dominant mechanisms for different volatile organic compounds (VOCs). Determining the mechanisms by which the target analyte is likely to interact with a sensing material will help narrow down potential sensing materials for a target analyte.

For example, ethanol contains an alcohol functional group and thus, ethanol is a polar molecule with a hydrogen attached to an oxygen. Therefore, ethanol is able to hydrogen bond. Consequently, a corresponding sensing material that would show affinity to ethanol should also be polar and ideally be able to hydrogen bond. Polymers that fall into this category are, for example, polymers containing alcohols, amines, and carboxylic acids.

\section{Case Studies}

This section provides examples and counterexamples of the dominant mechanisms that occur. In some cases, it is more difficult to determine the dominant sensing mechanism because more than one mechanisms have a strong effect and the mechanisms may compete with one another.

\section{Examples}

\section{Effect of Hydrogen Bonding}

Polyaniline (PANI) and poly ( $N$-methyl aniline) (PNMA) were evaluated using ethanol and acetone to determine if ethanol interacted with PANI through hydrogen bonding. Both PANI and PNMA were synthesized as described in Section 4.1 using their respective monomers: aniline (A.C.S. reagent, Sigma-Aldrich, Oakville, Ontario, Canada) and $N$-methyl aniline (A.C.S. reagent, Sigma-Aldrich, Oakville, Ontario, Canada). It was hypothesized that ethanol's $\mathrm{OH}$ 
group hydrogen bonded to the NH group on PANI. PNMA was chosen as a counterexample since PNMA is chemically similar to PANI, except the amine group on PNMA is "protected" through steric hindrance by a methyl group (see Figure 12). Acetone was chosen as a counterexample (to ethanol) since PANI may still hydrogen bond to the double bonded oxygen $(=\mathrm{O})$ on acetone, but acetone itself cannot hydrogen bond and thus would not sorb onto PNMA. It should be noted that acetone is a little larger than ethanol $\left(77.5 \mathrm{~cm}^{3} / \mathrm{mol}\right.$ and $62.6 \mathrm{~cm}^{3} / \mathrm{mol}$, respectively; however, acetone is more polar than ethanol (2.91 D and $1.69 \mathrm{D}$, respectively). Despite these differences, on the whole, acetone and ethanol are similar molecules.

(a)

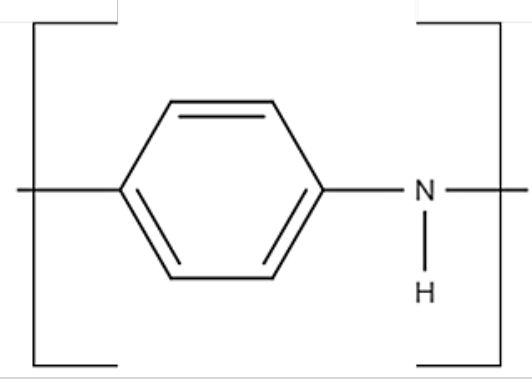

(b)

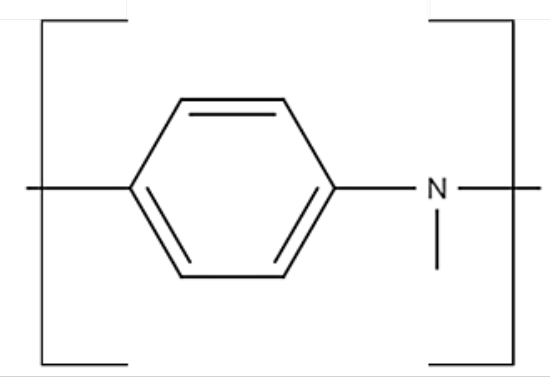

Figure 12. Schematic of (a) polyaniline (PANI) and (b) poly ( $N$-methyl aniline) (PNMA).

Acetone is able to act as a Lewis-base; however, PANI would prefer to hydrogen bond since the hydrogen in the amine on PANI is electron deficient and wants to gain electron density through hydrogen bonding. The electronegative oxygen (on acetone) will seek out the positively charged hydrogen, resulting in a hydrogen bond. The tertiary amine on PNMA will act as a Lewis-base and does not have a hydrogen attached to its amine able to hydrogen bond to acetone. Therefore, acetone is unable to bond with PNMA. However, ethanol is still capable of hydrogen bonding to the tertiary amine on PNMA because of the alcohol $(\mathrm{OH})$ group in ethanol.

Both PANI and PNMA were subjected to $5 \mathrm{ppm}$ of ethanol (balance of nitrogen) and $5.5 \mathrm{ppm}$ of acetone (balance of nitrogen), separately. The amount of gas (ethanol or acetone) that sorbed onto the sensing material (PANI or PNMA) was subsequently measured. It was found that significantly more ethanol and acetone sorbed onto PANI than onto PNMA. In addition, significantly more ethanol sorbed onto both PANI and PNMA than acetone (see Figure 13). 


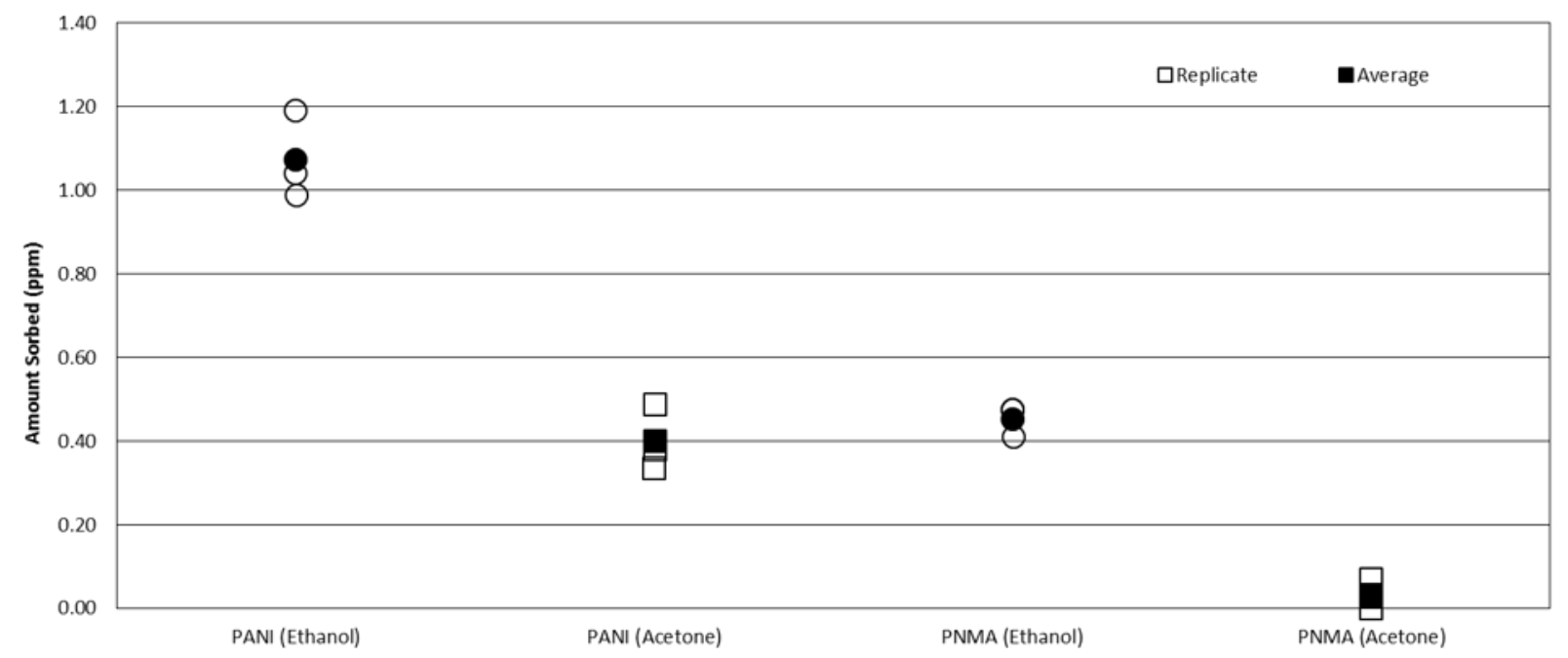

Figure 13. Amount of ethanol (circles) and acetone (squares) sorbed onto both PANI and PNMA.

Despite acetone being more polar than ethanol, acetone is only a hydrogen bond acceptor, which means that it doesn't have a hydrogen capable of hydrogen bonding. This results in acetone being attracted to both PANI and PNMA through electrostatic forces, but is limited in physically bonding with these polymeric sensing materials. Ethanol's ability to hydrogen bond allows it to sorb onto both PANI and PNMA. Since PANI is also able to hydrogen bond and PNMA is only a hydrogen bond acceptor, due to PNMA's a tertiary amine, PANI will more readily sorb both acetone and ethanol.

There is some steric hindrance that occurs as well, which enhances the difference in sorption between ethanol and acetone. Acetone is larger than ethanol and has a bulkier shape. Acetone is trigonal planar in shape, whereas ethanol is linear and has one less carbon atom. This means that acetone is more sterically hindered. It should be noted that the polar attractive forces and the steric repulsion do compete against one another and given that acetone is not that bulky, in general, the attractive forces are likely to win out, especially for PANI, where the amine is unprotected. However, the steric repulsion is more of an issue when it comes to PNMA, where the amine is somewhat "protected" by a methyl group, which would exert greater steric repulsion.

\section{Incorporation of Metal Oxide Dopants into a Polymeric Sensing Material}

The incorporation of a metal oxide nanoparticle into a polymer (doping) can improve both the sensitivity and selectivity of a sensing material. For example, doping poly (2,5-dimethyl aniline) (P25DMA) with just 5 wt. \% alumina $\left(\mathrm{Al}_{2} \mathrm{O}_{3}\right)$ improved both the sensitivity to ethanol, as well as the selectivity (see Figure 14). The P25DMA was synthesized using 2,5-dimethyl aniline (A.C.S. reagent, Sigma-Aldrich, Oakville, Ontario, Canada) with 5 wt. \% $\mathrm{Al}_{2} \mathrm{O}_{3}$ nanoparticles 
(particle size $<50$ nm, 10 wt. \% dispersion in $\mathrm{H}_{2} \mathrm{O}$, Sigma-Aldrich, Oakville, Ontario, Canada), as described in Section 4.1.

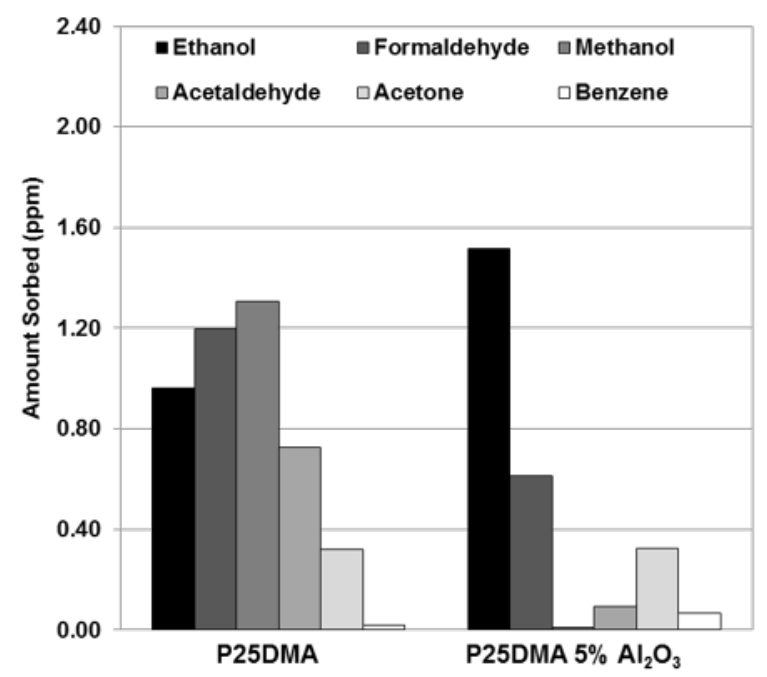

Figure 14. Sorption of different gases (left to right, ethanol, formaldehyde, methanol, acetaldehyde, acetone, and benzene) to P25DMA and P25DMA 5\% $\mathrm{Al}_{2} \mathrm{O}_{3}$.

$\mathrm{Al}_{2} \mathrm{O}_{3}$ was added to increase the sensitivity ${ }^{[84]}$ and selectivity of P25DMA to ethanol. ${ }^{[85]}$ Ethanol more readily decomposes on $\mathrm{Al}_{2} \mathrm{O}_{3}$ than other volatile organic compounds (VOCs) such as methanol and acetaldehyde. ${ }^{[86]}$ Therefore, ethanol is able to coordinate better with the $\mathrm{Al}$ and thus, adding $\mathrm{Al}_{2} \mathrm{O}_{3}$ should ideally improve the selectivity of P25DMA, which it did.

The addition of $\mathrm{Al}_{2} \mathrm{O}_{3}$ to P25DMA also changed the morphology of the sensing material. The addition of $\mathrm{Al}_{2} \mathrm{O}_{3}$ created "kinks" along the P25DMA chain, resulting in polymer chains that could not stack as neatly. This resulted in an increase in surface area available for the analytes to sorb to. In addition, the structure became more porous (see Figure 15), which also increased the number of sensing sites for the analytes to bond to. This increase in number of sensing sites improved the selectivity of the P25DMA. 

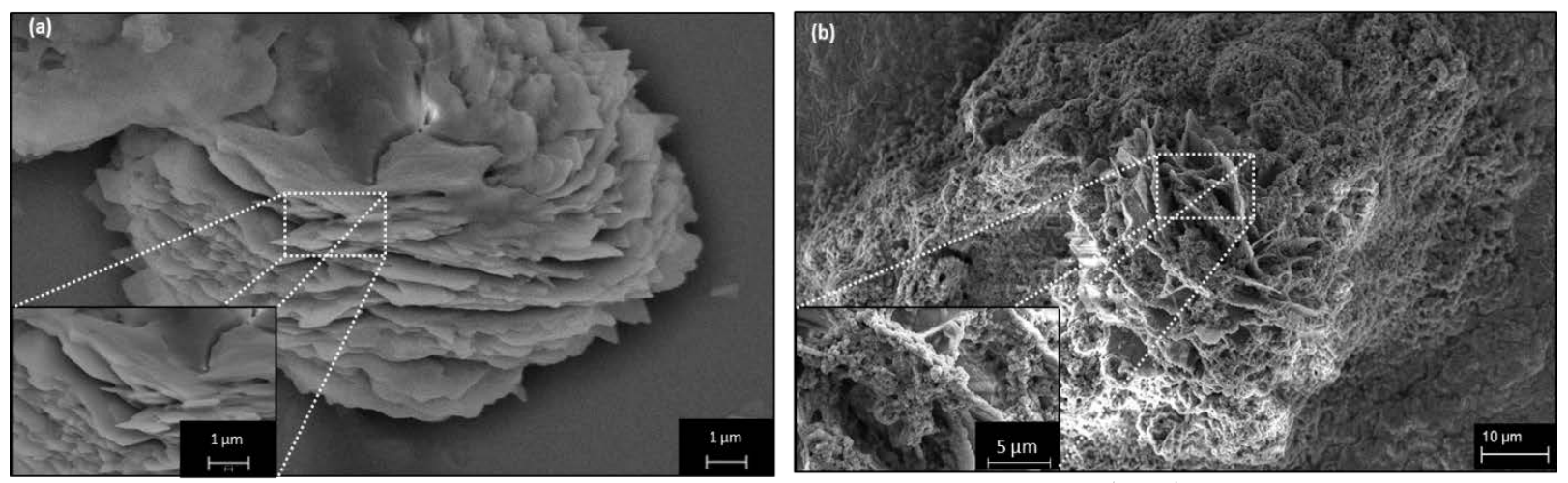

Figure 15. SEM images of (a) P25DMA and (b) P25DMA doped with $\mathrm{Al}_{2} \mathrm{O}_{3}$.

\section{Competing Mechanisms}

Poly (2,5-dimethyl aniline) (P25DMA) was doped with nickel oxide (NiO) nanoparticles and exposed to ethanol gas to evaluate P25DMA doped with $\mathrm{NiO}$ as a potential sensing material for ethanol (see Figure 16). The P25DMA was synthesized using 2,5-dimethyl aniline (A.C.S. reagent, Sigma-Aldrich, Oakville, Ontario, Canada), with 5 wt. \%, 10 wt. \%, and 20 wt. \% NiO nanoparticles (particle size $<50 \mathrm{~nm}$, concentration of 99.8\%, Sigma-Aldrich, Oakville, Ontario, Canada) as described in Section 4.1.

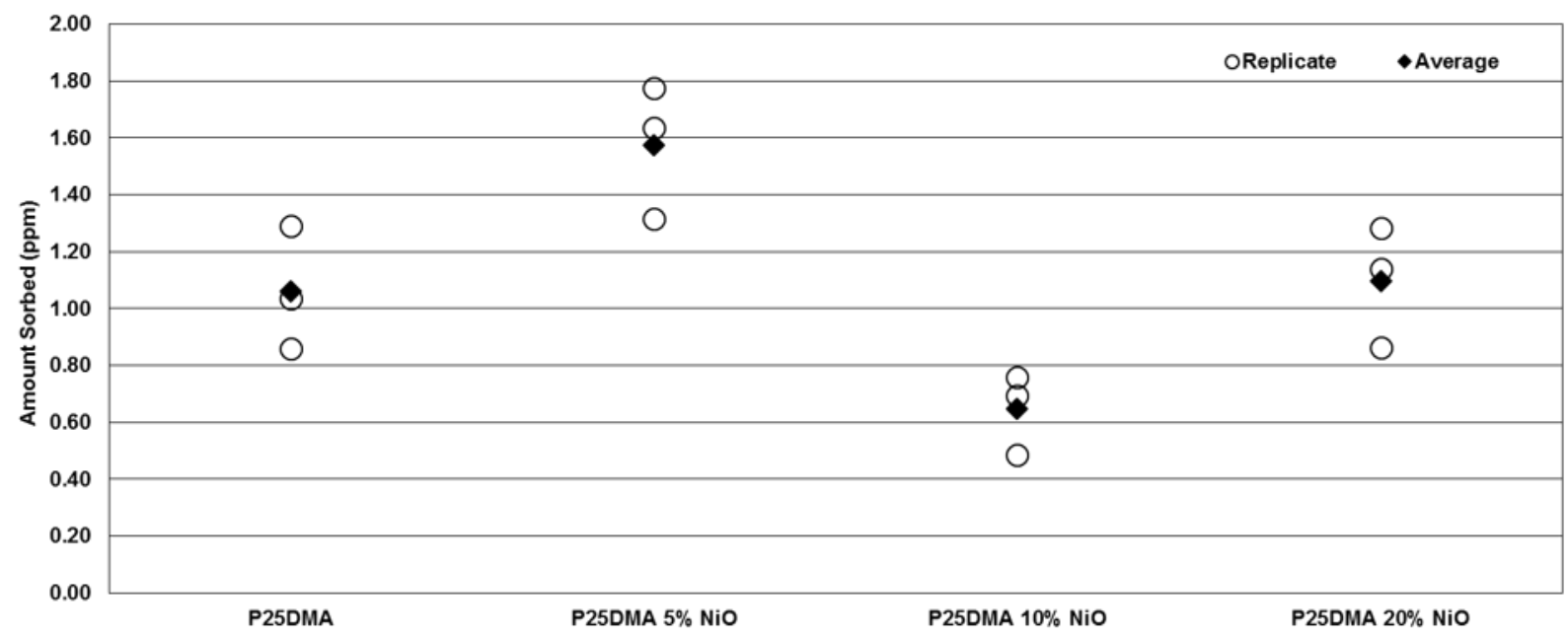

Figure 16. Ethanol sorption on P25DMA and P25DMA doped with different concentrations of $\mathrm{NiO}$.

P25DMA primarily interacts with ethanol through hydrogen bonding. Adding 5\% $\mathrm{NiO}$ created "kinks" in the polymer chain, where the P25DMA changed conformation to reduce strain caused by the bond between the $\mathrm{Ni}$ and the amine groups on P25DMA. ${ }^{[20]}$ This created larger interstitial spaces in the polymer and thus, improved diffusivity into the polymer. This resulted in the amount of ethanol sorbed which significantly increased for P25DMA 5\% NiO compared to the 
undoped P25DMA. Even with the added NiO, the dominant mechanism for P25DMA 5\% $\mathrm{NiO}$ was still hydrogen bonding, although metal coordination did play a minor role in the improved sorption observed.

Further increasing the amount of $\mathrm{NiO}$ to $10 \mathrm{wt}$ \% resulted in a large and significant drop in ethanol sorption, likely due to competing mechanisms. At a concentration of $10 \mathrm{wt}$ \%, metal coordination likely began to take over. The larger and more numerous interstitial spaces created by the kinks in the polymer chain would have increased the diffusion into the polymer matrix where most of the $\mathrm{NiO}$ resided. Note that the $\mathrm{NiO}$ bound to multiple amine groups in the polymers, thereby reducing the number of sites (amines) to which ethanol hydrogen bonded. This reduction in sensing sites coupled with reduced access to NiO (where metal coordination occurs) resulted in a reduced amount of ethanol sorbed.

By increasing the amount of $\mathrm{NiO}$ to $20 \mathrm{wt}$. \%, the amount of ethanol sorbed increased again, although not back to the level of P25DMA 5\% NiO. This increase in ethanol sorption from 10\% to $20 \% \mathrm{NiO}$ was likely due to the higher availability of $\mathrm{NiO}$ with which ethanol was able to coordinate. P25DMA 20\% NiO had the most kinks in the polymer chains and thus, an increased number of larger interstitial spaces to improve diffusion (and therefore, less steric hindrance). In addition, the increased amount of $\mathrm{NiO}$ allowed more ethanol to coordinate to the $\mathrm{Ni}$, despite the $\mathrm{NiO}$ reducing the number of amines on the P25DMA to which the ethanol could hydrogen bond.

In the case for P25DMA doped with $\mathrm{NiO}$, two competing mechanisms dominated. At low concentrations of $\mathrm{NiO}$ (5 wt. \%), hydrogen bonding dominated and resulted in a large amount of ethanol sorption. As more $\mathrm{NiO}$ was added, the $\mathrm{NiO}$ coordinated to more and more amine sites on the P25DMA, significantly reducing the number of amines available to which ethanol could hydrogen bond. However, as the concentration of $\mathrm{NiO}$ increased, the dominance of metal coordination increased. At 20 wt. \%, the increased $\mathrm{NiO}$ content allowed metal coordination to dominate due to the availability of $\mathrm{NiO}$ and reduction in hydrogen bonding sites on the P25DMA.

\section{Counterexamples}

Sometimes the dominant mechanism for a target analyte and/or sensing material can have detrimental effects on sensitivity and selectivity. For example, a sensing material that is capable of hydrogen bonding, such as poly (ethyleneimine) (PEI), may sorb interferents more preferentially or may bind too strongly to certain analytes to be useful. Another example is when a metal oxide is added to improve the sensing properties of a polymer, but instead it is either not incorporated into the polymer matrix or destroys the polymer matrix, resulting simply in polymer coated nanoparticles. 


\section{Competing Analytes (Poor Selectivity)}

Poly (ethyleneimine) (PEI) was chosen as a potential sensing material for ethanol due to its numerous amine groups (see Figure 17). PEI (50 wt. \% in water, Sigma-Aldrich, Oakville, Ontario, Canada) was dried at room temperature $\left(21^{\circ} \mathrm{C}\right)$ for two months, then purged with nitrogen (5.0 grade) for 4 hours before being evaluated with $5 \mathrm{ppm}$ of ethanol (balance of nitrogen). It was found that PEI sorbed only $0.05 \mathrm{ppm}$, which can be considered negligible, since the error was determined as $1 \%$ (based on three independent replicates).

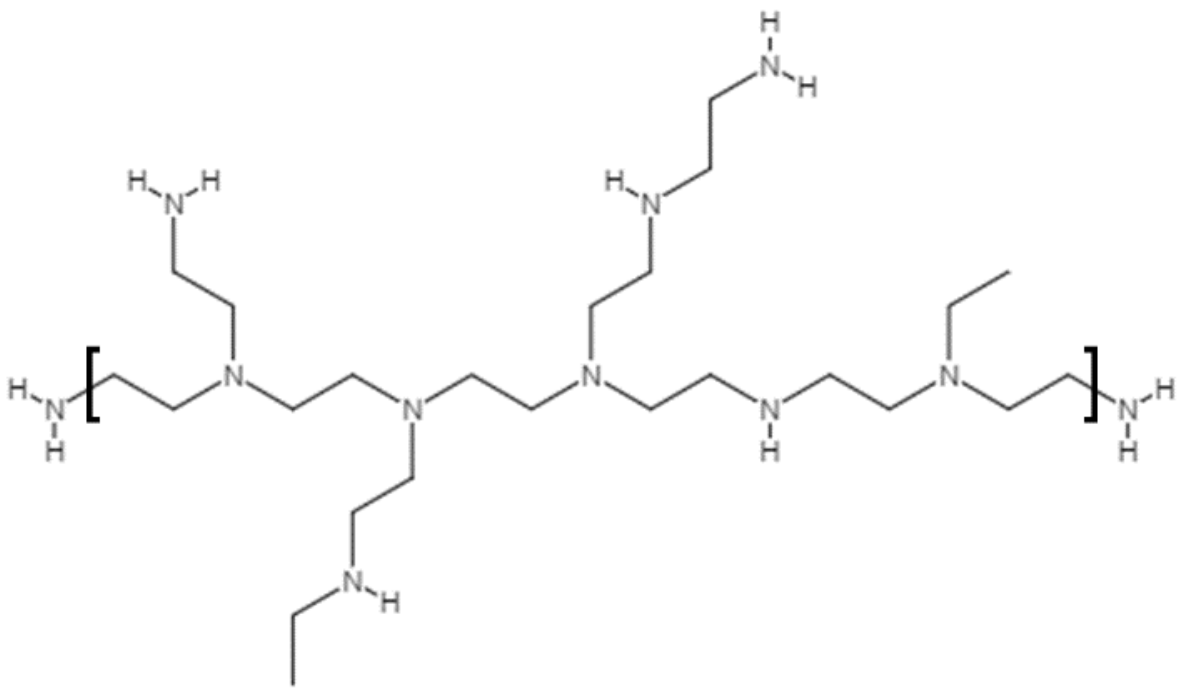

Figure 17. Schematic of poly (ethyleneimine) (PEI).

Based on the chemical structure of PEI, it would appear that there is a high density of sensing sites due to all the amines present. In addition, the branching would reduce the polymers ability to pack, increasing the interstitial spaces between the polymer chains, thereby improving diffusion of an analyte into the polymeric material. However, because of these amine groups, PEI is extremely hydrophilic and thus, PEI was saturated with water molecules, even after PEI had been dried, which left no open sensing sites for ethanol. A few ethanol molecules may have sorbed onto the water molecules through hydrogen bonding, but it was a negligible amount.

While it may have been possible to remove more water from the PEI, its use as a sensing material is limited due to its affinity to water. In atmospheric conditions, where water vapour is present (relative humidity), water vapour will preferentially bind to PEI since it is much more polar than any other polar analyte. Note that PEI has been used in sensor applications; however, it has been combined with other materials such as poly (vinyl alcohol) for a formaldehyde sensor ${ }^{[50]}$ or combined with multi-walled carbon nanotubes for a humidity sensor. ${ }^{[87]}$ 
There are cases where a metal oxide either does not bind to the polymer at all or only a small percentage will be incorporated. In the case where the metal oxide is not incorporated into the polymer, the polymer is not considered doped with the metal oxide. In the case where only a small percentage of metal oxide is incorporated, despite adding more metal oxide (i.e. only $5 \%$ of a metal oxide is taken up, despite $20 \%$ being available), the polymer is considered doped. These two cases are the result of poor coordination between the metal oxide and the polymer.

Copper (II) oxide (CuO) (particle size $<50 \mathrm{~nm}$, Sigma-Aldrich, Oakville, Ontario, Canada) was polymerized with 2,5-dimethyl aniline (A.C.S. reagent, Sigma-Aldrich, Oakville, Ontario, Canada) at three concentrations of $\mathrm{CuO}$ (5 wt.\%, $10 \mathrm{wt} \%$, and $20 \mathrm{wt} . \%$, based on amount added during polymerization) to form a doped poly (2,5-dimethyl aniline) (P25DMA). Note that the three samples will be referred to as P25DMA 5\% CuO, P25DMA 10\% CuO, and P25DMA 20\% $\mathrm{CuO}$. However, none of the $\mathrm{CuO}$ was incorporated into the final polymer. The lack of $\mathrm{CuO}$ was confirmed by electron dispersive spectroscopy (Ametek EDAX, New Jersey, USA); see Table 11. In addition, there was no significant difference between the amount of ethanol sorbed between P25DMA 5\% CuO, P25DMA 10\% CuO, and P25DMA 20\% CuO (see Figure 18) and the scanning electron microscopy (SEM) images showed that P25DMA 5\% CuO, P25DMA 10\% $\mathrm{CuO}$, and P25DMA 20\% CuO all had similar morphologies (see Figure 19). It was, however, interesting to note that the morphology of the P25DMA made in the presence of $\mathrm{CuO}$ had a different morphology and sorption response to ethanol than P25DMA made without any dopant added during polymerization (see Figures 18 and 19).

Table 11. EDAX Measurements for P25DMA Doped with CuO

\begin{tabular}{cc}
\hline Polymeric Nanocomposite & $\begin{array}{c}\text { Weight Percent } \\
\text { of } \mathbf{C u}\end{array}$ \\
\hline P25DMA 5\% CuO & 0.16 \\
P25DMA 10\% CuO & 0.07 \\
P25DMA 20\% CuO & 0.11 \\
\hline
\end{tabular}




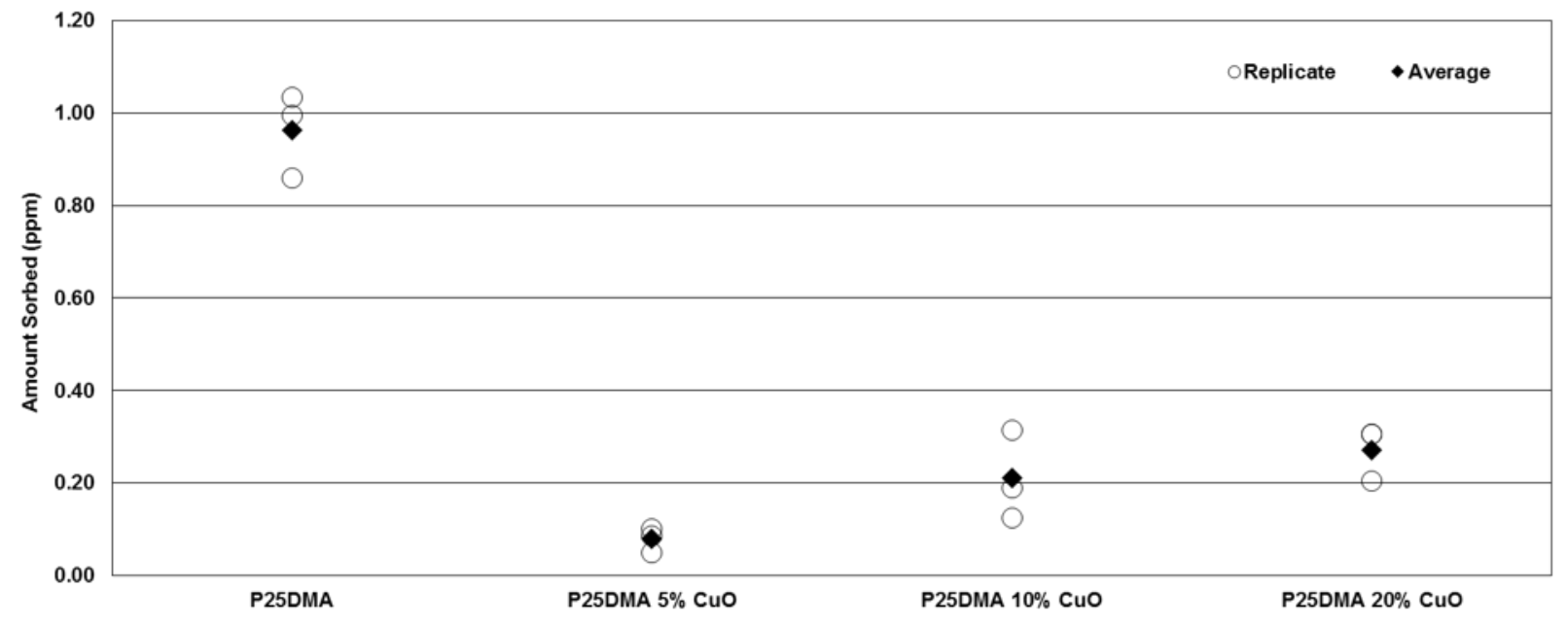

Figure 18. Amount of ethanol sorbed onto P25DMA doped with $\mathrm{CuO}$.
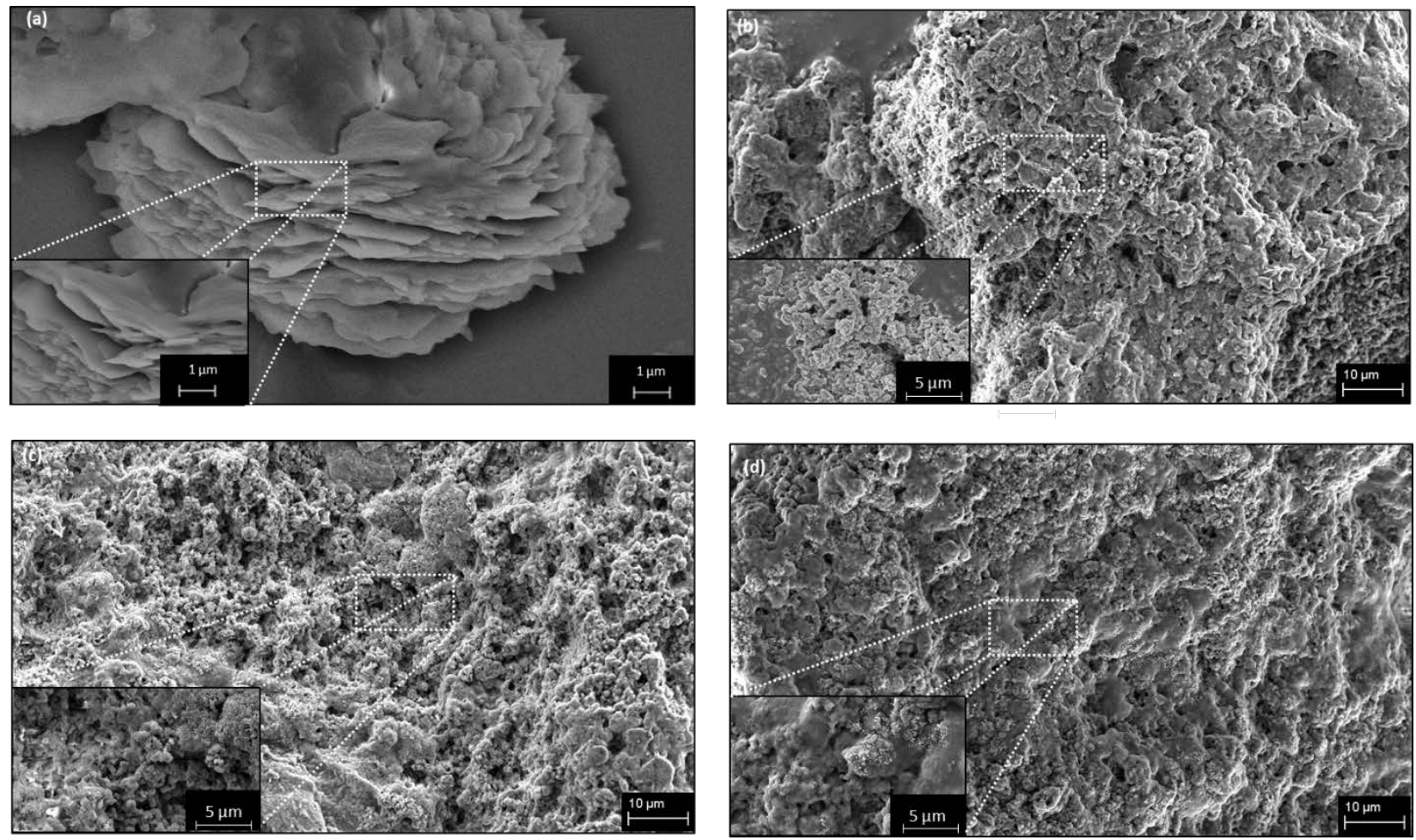

Figure 19. SEM images of (a) P25DMA, (b) P25DMA doped with 5\% CuO, (c) P25DMA doped with 10\% CuO, and (d) P25DMA doped with 20\% CuO.

This suggests that despite the $\mathrm{CuO}$ not incorporating into the P25DMA matrix, it did have an effect on the synthesis. It is likely that the $\mathrm{CuO}$ created "kinks" along the P25DMA chain as the polymer attempted to conform around a $\mathrm{CuO}$ nanoparticle as the polymer chain grew; however the strain was too great and the weak bond between $\mathrm{Cu}$ and the P25DMA would break to relieve this strain. The "kinks" would, however, remain and result in a more porous morphology since the polymer chains would not be able to stack more closely together. Note that a more porous 
morphology does not necessarily mean the polymer has a larger number of accessible sensing sites. This is the case for the CuO doped P25DMA versus the undoped P25DMA.

The conformational strain of a polymer chain when the polymer is bound to the metal oxide nanoparticle results in a polymer coated nanoparticle, as is the case of P25DMA with 20 wt. \% zinc oxide $(\mathrm{ZnO}) .{ }^{[88]}$ By coating the $\mathrm{ZnO}$ nanoparticle with P25DMA, the $\mathrm{ZnO}$ is no longer accessible by the analyte and thus, the $\mathrm{ZnO}$ cannot interact with the analyte. In addition, the P25DMA is essentially 'destroyed' and thus the $\mathrm{ZnO}$ decreases the number of sorption sites on P25DMA, resulting in significantly reduced sensing ability of the P25DMA to ethanol. ${ }^{\text {[21] }}$

Both of these examples, P25DMA with $\mathrm{CuO}$ and $\mathrm{ZnO}$, show that choosing dopants that coordinate well with the polymer matrix is important. However, this may not always be evident, and as such, dopants are chosen based on their likelihood to improve sorption of the target analyte. Therefore, preliminary screening tests are important to determine if the dopant (metal oxide) is incorporated well into the polymer matrix and if the dopant has an effect on the sensing properties.

\section{Practical Prescriptions and Applied Example}

\section{Practical Prescriptions}

The prescriptions herein are for designing and selecting polymeric sensing materials for volatile organic compounds (VOC); see Figure 20 for an overview. They take into consideration the previously described dominant sensing mechanisms with which the analytes and sensing materials interact (see Sections 2 and 3).

When designing a sensing material for a target analyte, it is best to begin by looking at the chemistry of the target analyte. Determining the type of functional group(s) on the target analyte will help narrow down the types of polymers that could work as sensing materials. In addition, the size of the target analyte is a consideration. If the target analyte is bulky such as benzene or trimethylamine, then a polymer whose chains do not pack as tightly (i.e. has larger interstitial spaces) would be better; however, a small molecule such as methanol or formaldehyde can more easily penetrate smaller interstitial spaces due to reduced steric hindrance.

The type of functional groups on the target analyte will determine the dominant mechanisms with which the target analyte and the polymeric sensing material interact. See Section 3 for further details about which mechanisms dominate for which functional groups. Based on the sensing mechanisms, potential polymer classes can be selected, which will be further refined by other constraints. 
The next step is to look at the target application. The target application will have some constraints such as operational temperature and environmental stability. The polymer must be able to remain in its glassy state at the operating temperature (range). Therefore, the glass transition temperature $\left(\mathrm{T}_{\mathrm{g}}\right)$ must be above the operational temperature of the sensor. In addition, the polymer must have good mechanical and environmental stability to withstand repeated and long term use.

The main constraint is sensitivity (detection limit). For a particular application, the detection limit of a sensor must be lower than the target limit. In general, a sensing material with more "sensing sites" has a lower limit of detection and is thus more sensitive. The more accessible (available) sensing sites are on the surface of the sensing material; thus, a morphology with high surface area-to-volume ratios is best.

The target application will also determine the types of typical analytes (interferents) present with the analyte, as well as typical concentrations of all analytes. If the interferents are present at an order of magnitude (or more) lower than the target analyte, then those interferents may not appreciably interact with a sensing material. In addition, the list of potential polymers may be reduced by considering the chemistry and functional groups of the interferents. For example, the response from larger interferents can be reduced through steric hindrance since the larger interferents will be repelled by steric effects and thus not be able to sorb onto the sensing material and produce a response. Therefore, polymers with bulkier side groups/chains may be eliminated from the list of potential polymers. Another example is using hydrophobic and hydrophilic copolymers to reduce a response caused by water vapour (humidity).

The type of sensor used will significantly affect the types of polymers considered. If a resistive (conductive)-based sensor is used, then the sensing material must be conductive. Therefore, a conductive polymer is needed for resistive type sensors. Currently, resistive type sensors are most commonly used. Other types of sensors include capacitive-based sensors, where a conductive polymer may hinder the sensor performance, and mass-based sensors, where polymeric sensing materials are advantageous because they are of light weight compared to metal and metal oxide sensing materials.

The list of potential polymers has now been reduced through dominant mechanisms, application constraints, and types of sensor. The resulting polymers can also be modified by adding, removing, and/or changing some functional groups on a polymer backbone. This can be done to improve any number of properties. Two or more polymers can be combined, creating a copolymer to change the properties. In addition, dopants can also be added. In some cases, dopants can be used to make a polymer conductive, such as adding acid to polyaniline. In many cases, metal and metal oxide dopants are added to improve the sensitivity and/or selectivity of 
the polymeric material. It is important to note that not all metals are able to coordinate with all polymers.

Once a final list of potential polymers has been selected, they can be ranked in terms of what may be the most effective in terms of sensitivity and/or selectivity. These polymers can now be synthesized and evaluated as sensing materials for the target analyte.

Note that selection of potential sensing materials is a two pronged approach. The selection combines the chemical nature of the target analyte and how it is likely to interact with a polymeric sensing material with the practical constraints placed on the application of the final sensor. Therefore, when looking at the chart in Figure 20, begin at the top. There are three paths (factors) to consider: target analyte, target application constraints, and typical interferents. Combining these three factors will result in a set of potential polymeric materials. Next, dopants can also be added. These polymers (with or without dopants) can then be evaluated as sensing materials for the target analyte and application. 

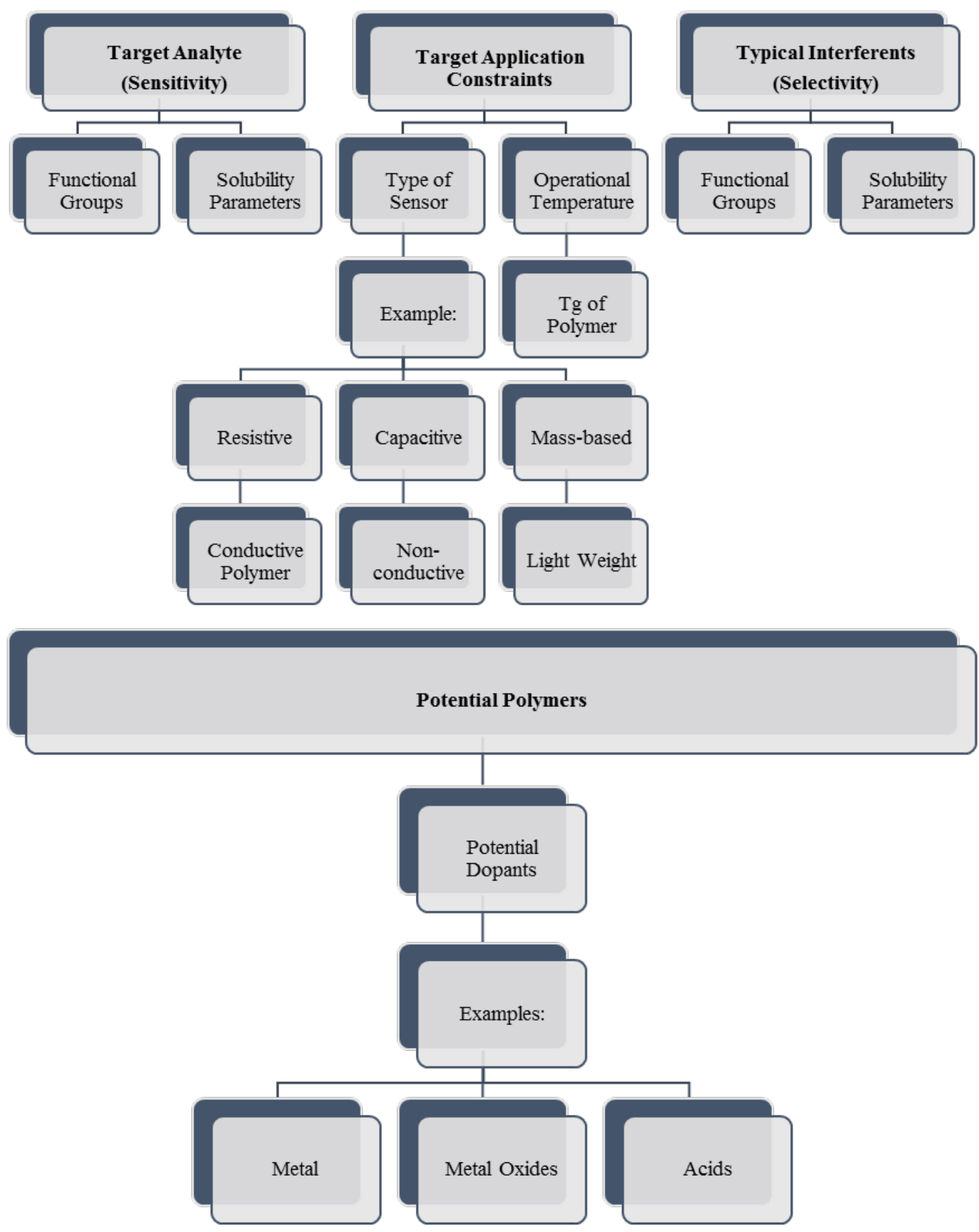

Figure 20. Prescription Flow Chart for Sensing Material Selection.

\section{Polymeric Sensing Material Selection Example}

As an example, an ethanol gas sensor will be used, with a target detection limit of $5 \mathrm{ppm}$. This sensor will typically operate at room temperature (around $21^{\circ} \mathrm{C}$ ) and may be either a resistive or 
mass-based sensor. The sensor will be used where appreciable amounts of methanol and acetone may also be present as interferents.

Initially, looking at ethanol, it has an alcohol group and therefore, it is able to hydrogen bond. It can also act as a Lewis-base; however, hydrogen bonding is the dominant mechanism. Therefore, potential polymers should include amines, alcohols, carboxylic acids, ethers, esters, amides, etc. This is a long list that needs to be pared down. For this example, a list of 12 potential polymers will be initially considered (see Table 12).

For a sensor working at room temperature, the polymers need to be in a glassy state above room temperature. Given that sensors are often pushed outside their typical operational range, the sensing material must not soften considerably or begin to flow. Therefore, for this application which can result in storage near $50{ }^{\circ} \mathrm{C}$, a $\mathrm{T}_{\mathrm{g}}$ above $60{ }^{\circ} \mathrm{C}$ is preferable. This drops the list of 12 candidates in Table 12 down to 7.

Looking at the functional groups of the main interferents (acetone and methanol) reduced the list of potential materials further. Methanol, similar to ethanol, is also an alcohol and thus, is also able to hydrogen bond. Acetone, on the other hand, cannot hydrogen bond, but as a ketone, will behave as a Lewis base. Therefore, keeping polymers that are not able to hydrogen bond, but have oxygen or nitrogen that ethanol is able to hydrogen bond to may improve selectivity. Therefore, the $\mathrm{OH}, \mathrm{COOH}$, and $\mathrm{NH}$ functionalized polymer chains will be eliminated, leaving 4 candidate polymers at this stage, namely, PETE, PMMA, PVP, and PPO.

A check with the Hildebrand solubility parameters, where ethanol is $26.6 \mathrm{MPa}^{1 / 2}$, shows that the Hildebrand solubility parameter of PPy is $25.15 \mathrm{MPa}^{1 / 2}$, which is close to that of ethanol. Therefore PPy will be added back to the list, bringing the number up to 5 potential polymeric sensing materials. PETE (21.9 $\mathrm{MPa}^{1 / 2}$ ) and PPO (19.6 $\mathrm{MPa}^{1 / 2}$ ) were the most different in terms of Hildebrand solubility parameters. To reduce the list to 4 potential polymers, PETE was eliminated and PPO was kept because PPO is conductive and PETE is not. This leaves 2 polymers that are conductive (PPy and $\mathrm{PPO}$ ) and 2 polymers that are non-conductive (PMMA and PVP). This allows for flexibility on the type of sensor that may be used. 
Table 12. Potential Polymeric Sensing Materials for Ethanol

\begin{tabular}{|c|c|c|c|c|}
\hline Polymer & 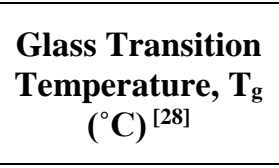 & $\begin{array}{l}\text { Hildebrand } \\
\text { Solubility } \\
\text { Parameter } \\
\left(\mathrm{MPa}^{1 / 2}\right)^{[28]} \\
\end{array}$ & Structure & $\begin{array}{c}\text { Functional } \\
\text { Groups }\end{array}$ \\
\hline $\begin{array}{l}\text { Poly (ethylene oxide) } \\
\text { (PEO) }\end{array}$ & -43 & 19.9 & & $-\mathrm{O}-$ \\
\hline $\begin{array}{l}\text { Poly (vinyl acetate) } \\
\text { (PVAc) }\end{array}$ & 30 & 25.66 & & COOR \\
\hline $\begin{array}{l}\text { Polyamide } \\
\text { (PA) }\end{array}$ & 50 & 23.02 & & CNOR \\
\hline $\begin{array}{l}\text { Poly (lactic acid) } \\
\text { (PLA) }\end{array}$ & 57 & 21 & & COOR \\
\hline $\begin{array}{l}\text { Poly (ethylene } \\
\text { terephthalate) } \\
\text { (PETE) }\end{array}$ & 67 & 21.9 & & COOR x2 \\
\hline $\begin{array}{c}\text { Poly (vinyl alcohol) } \\
\text { (PVA) }\end{array}$ & 85 & 21.7 & & $\mathrm{OH}$ \\
\hline $\begin{array}{l}\text { Polyaniline } \\
\text { (PANI) }\end{array}$ & 100 & $22.2^{[30]}$ & & $\mathrm{NH}$ \\
\hline $\begin{array}{l}\text { Poly (methyl } \\
\text { methacrylate) } \\
\text { (PMMA) }\end{array}$ & 105 & 22.8 & & COOR \\
\hline $\begin{array}{l}\text { Poly (acrylic acid) } \\
\text { (PAA) }\end{array}$ & 106 & 19.2 & & $\mathrm{COOH}$ \\
\hline $\begin{array}{l}\text { Poly (vinyl } \\
\text { pyrrolidone) } \\
\text { (PVP) }\end{array}$ & 128 & 25.6 & & CONR \\
\hline $\begin{array}{l}\text { Poly (2,6-dimethyl- } \\
\text { 1,4-phenylene oxide) } \\
\text { (PPO) }\end{array}$ & 215 & $19.6^{[31]}$ & & $-\mathrm{O}-$ \\
\hline $\begin{array}{l}\text { Polypyrrole } \\
\text { (PРy) }\end{array}$ & 270 & $25.2^{[32]}$ & & $\mathrm{NH}$ \\
\hline
\end{tabular}


These four polymers (PMMA, PVP, PPO, and PPy) were evaluated with respect to their sorption of ethanol, methanol, and acetone. PMMA (Average $\mathrm{M}_{\mathrm{w}}=15,000$, Sigma-Aldrich, Oakville, Ontario, Canada), PVP (Average $\mathrm{M}_{\mathrm{w}}=40,000$, Sigma-Aldrich, Oakville, Ontario, Canada), PPO (Average $\mathrm{M}_{\mathrm{w}}=30,000$ Sigma-Aldrich, Oakville, Ontario, Canada), and PPy (Conductivity 10 $50 \mathrm{~S} / \mathrm{cm}$, pressed pellet, Sigma-Aldrich, Oakville, Ontario, Canada) were all used as obtained, without further modification. The polymers were prepared in round bottom flasks and tested as described in Section 4.3.

All four polymers showed good sorption of ethanol. In addition, all four polymers showed poorer sorption of methanol and acetone (see Figure 21). Therefore, all four polymers had good selectivity towards ethanol with respect to methanol and especially to acetone. From here, only a couple of polymers need to be deposited onto a sensor for further evaluation. If a resistive type sensor is chosen, then PPy and PPO can be used; if a mass-based sensor is selected, then any of the four polymers could be employed; however, PVP had the best selectivity and thus would be the best choice, despite PVP sorbing the least ethanol of the four polymers. This demonstrates that the practical prescriptions can significantly improve the efficiency of choosing (and further testing) potential sensing materials. When coupled with preliminary evaluation of a sensing material's sorption characteristics to specific gas analytes, the cost of deposition and sensor testing is also significantly reduced.

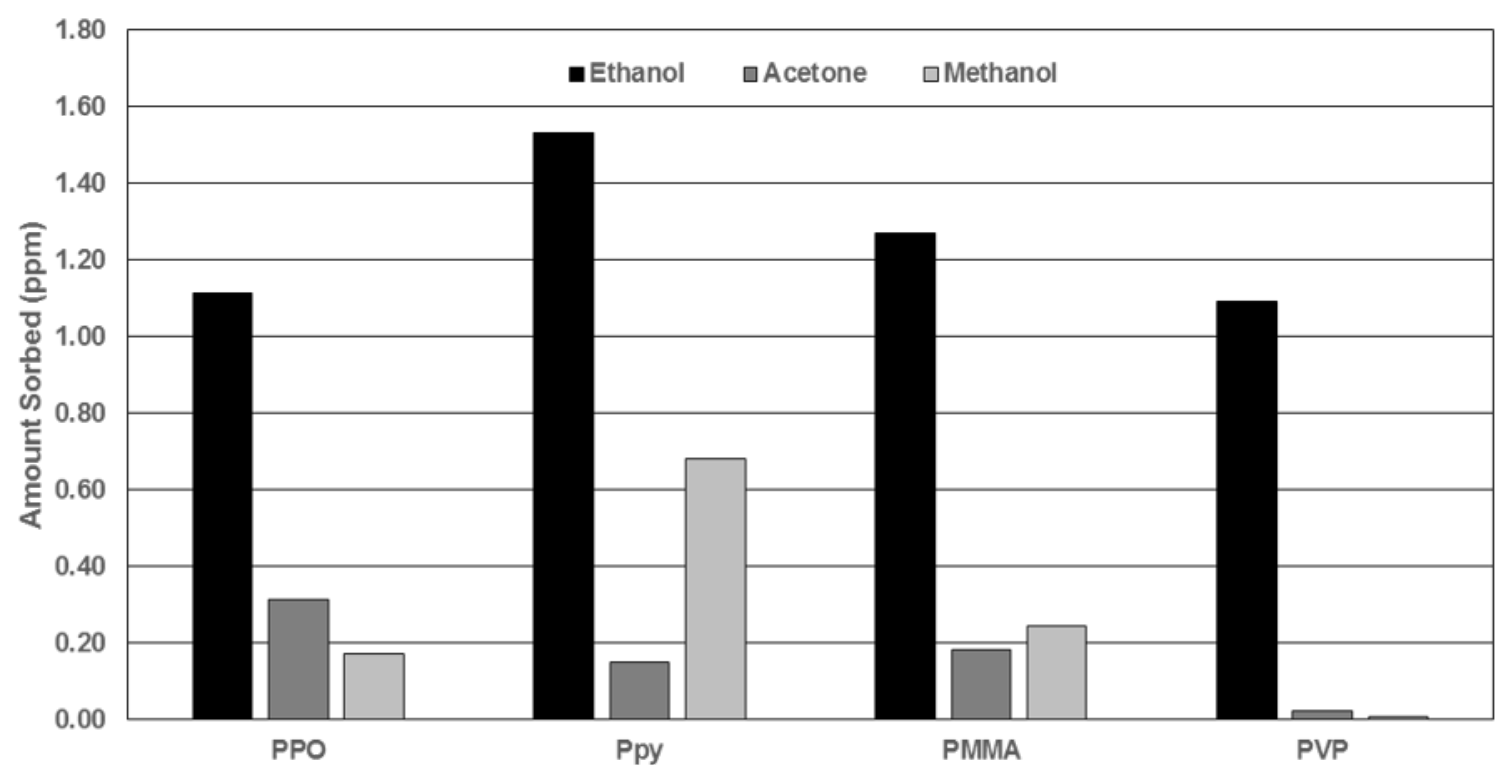

Figure 21. Sorption of the four polymers to ethanol, methanol, and acetone.

\section{Concluding Remarks}

By examining the way an analyte interacts with a sensing material, it is possible to determine the dominant sensing mechanisms. We examined a multitude of potential sensing mechanisms and 
how they may interact with one another (or counteract each other). Using this knowledge, the dominant sensing mechanisms for six different types of volatile organic compounds (VOCs) were discussed in more detail. Compiling (highly scattered) sensing mechanisms from the literature into a single source has enabled a better understanding of how sensing materials interact with gas analytes and improved the way sensing materials can be designed and chosen.

Using the practical prescriptions laid out, it is possible to improve the way sensing materials are designed, beginning with a target application. This approach is more efficient, since less experimental work is needed for testing (since time consuming trial-and-error scenarios are largely eliminated). In addition, this approach reduces the costs associated with synthesizing new materials, depositing sensing materials onto sensors, and the number and type of sensors having to be used.

\section{Acknowledgements}

The authors are grateful for financial support from the Natural Sciences and Engineering Research Council (NSERC) of Canada, the Canada Research (CRC) program, and AUTO21.

\section{References}

[1] WHO Regional Office for Europe, Guidelines for Indoor Air Quality: Selected Pollutants, Copenhagen, Denmark, 2010.

[2] C. Deng, J. Zhang, X. Yu, W. Zhang, X. Zhang, J Chromatogr B 2004; 810, 269

[3] R. Solomon, J. Cardy, I. Noble, R. Wulkan, The 2012 Provincial and Territorial Legislative Review, MADD, 2012.

[4] R. W. Howarth, R. Santoro, A. Ingraffea, Climatic Change 2011; 106, 679.

[5] C. Wang, L. Yin, L. Zhang, Y. Qi, N. Lun, N. Liu, Langmuir 2010; 26, 12841.

[6] A. K. Srivastava, Sens Act B 2003; 96, 24.

[7] K. Suri, S. Annapoorni, A. K. Sarkar, R. P. Tandon, Sens Act B 2002; 81, 277.

[8] V. Talwar, O. Singh, R. C. Singh, Sens Act B 2014; 191, 276.

[9] Y. S. Jung, W. C. Jung, H. L. Tuller, C. A. Ross, Nano Lett 2008; 8, 3776.

[10] K. M. E. Stewart, N. T. McManus, E. Abdel-Rahman, A. Penlidis, J Macromol Sci A 2012; $49,1$.

[11] K. M. E. Stewart, A. Penlidis, Macromol Symp 2016; 360, 123.

[12] C. A. Coulson, $T$ Faraday Soc 1942; 38, 433.

[13] C. K. Tan, D. J. Blackwood, Sens Act B 2000; 71, 184.

[14] K. Hirayama, Y. Sakai, K. Kameoka, K. Noda, R. Naganawa, Sens Act B 2002; 86, 20.

[15] L. L. Miller, R. G. Dunn, D. C. Tully, D. A. Tomalia, J Am Chem Soc 1997; 119, 1005. 
[16] B. Xiong, Y. Zhou, Y. Zhao, J. Wang, X. Chen, R. O’Hayre, Z. Shao, Carbon 2013; 52, 181.

[17] H. Wang, Y. Wang, Z. Zhu, A. Sapi, K. An, G. Kennedy, W. D. Michalak, G. A. Somorjai, Nano Lett 2013; 13, 2976.

[18] J. Wang, P. Zeng, J.-Q. Qi, P.-J. Yao, Sens Act B 2009; 136, 399.

[19] C.-Y. Lee, P.-R. Hsieh, C.-H. Lin, P.-C. Chou, L.-M. Fu, C.-M. Chiang, Microsyst Technol 2006; 12, 893.

[20] J. Han, G. Song, R. Guo, J Polym Sci A 2006; 44, 4229.

[21] K. M. E. Stewart, W. T. Chen, R. R. Mansour, A. Penlidis, J Appl Polym Sci 2015; 132, 42259.

[22] J. W. Grate, M. H. Abraham, Sens Act B 1991; 3, 85.

[23] H. Bai, G. Shi, Sensors 2007; 7, 267.

[24] M. Joulazadeh, A. H. Navarchian, M. Niroomand, Adv Polym Tech 2014; 33, DOI: 10.1002/adv.21461.

[25] J. M. Slater, J. Paynter, E. J. Watt, Analyst 1993; 118, 379.

[26] B. Vercelli, S. Zecchin, N. Comisso, G. Zotti, A. Berlin, E. Dalcanale, L. Groenendaal, Chem Mater 2002; 14, 4768.

[27] B. Bonavoglia, G. Storti, M. Morbidelli, A. Rajendran, M. Mazzotti, J Polym Sci B 2006; 44, 1531.

[28] J. Bandrup, E. H. Immergut, E. A. Grulke, Polymer Handbook Fourth Edition, John and Wiley Sons, Inc., USA, 1999.

[29] T. Itoh, I. Matsubara, W. Shin, N. Izu, Chem Lett 2007; 36, 100.

[30] L. W. Shacklette, C. C. Han, MRS Proceedings 1993; 328, 157.

[31] J. E. Puskas, Y. Kwon, V. Altstädt, M. Kontopoulou, Polymer 2007; 48, 590.

[32] F. P. Bradner, J. S. Shapiro, H. J. Bowley, D. L. Gerrard, W. Maddams, Polymer 1989; 30, 914.

[33] C. M. Hansen, Hansen Solubility Parameters: A User's Handbook, Second Edition, CRC Press, United States of America, 2007.

[34] O. K. Duaij, A. Alghamdi, Z. Y. Al-Sigh, J Chromatogr A 2013; 1291, 137.

[35] L. W. Shacklette, Synthetic Met 1994; 65, 123.

[36] A. A. Athawale, S. V. Bhagwat, P. P. Katre, Sens Act B 2006; 114, 263.

[37] Y. Gao, X. Li, J. Gong, B. Fan, Z. Su, L. Qu, J Phys Chem C 2008; 112, 8215.

[38] J.-S. Kim, S.-O. Sohn, J.-S. Huh, Sens Act B 2005; 108, 409.

[39] A. L. Kukla, Y. M. Shirshov, S. A. Piletsky, Sens Act B 1996; 37, 135.

[40] A. A. Athawale, M. V. Kulkarni, Sens Act B 2000; 67, 173.

[41] M. Babei, N. Alizadeh, Sens Act B 2013; 183, 617.

[42] M. F. Mabrook, C. Pearson, M. C. Petty, Sens Act B 2006; 115, 547.

[43] D. Das, P. Choudhury, L. J. Borthakur, I. R. Kamrupi, U. Gogoi, S. K. Dolui, Sens Act B 2014; 199, 320.

[44] J. M. Fonner, C. E. Schmidt, P. Ren, Polymer 2010; 51, 4985. 
[45] S. Zhan, D. Li, S. Liang, X. Chen, X. Li. Sensors 2013; 13, 4378.

[46] W. T. Chen, K. M. E. Stewart, C. K. Yang, R. R. Mansour, J. Carroll, A. Penlidis, IEEE T Microw Theory 2015; 63, 4157.

[47] J. Zhang, P. Guan, W. Li, Z. Shi, H. Zhai, Instrum Sci Technol 2016; 44, 249.

[48] S. Antwi-Boampong, J. J. BelBruno, Sens Act B 2013; 182, 300.

[49] T. Alizadeh, L. H. Soltani, J Hazard Mater 2013; 248, 401.

[50] X. Wang, B. Ding, M. Sun, J. Yu, G. Sun, Sens Act B 2010; 144, 11.

[51] L. Lefferts, J. G. van Ommen, J. R. H. Ross, Appl Catal 1986; 23, 385.

[52] S. Velusamy, M. Ahamed, T. Punniyamurthy, Org Lett 2004; 6, 4821.

[53] S. K. Maiti, K. M. Abdul Malik, R. Bhattacharyya, Inorg Chem Commun 2004; 7, 823.

[54] L. Ruangchuay, A. Sirivat, J. Schwank, Talanta 2003; 60, 25.

[55] D. Zhang, A. Liu, H. Chang, B. Xia, RSC Advances 2015; 5, 3016.

[56] J.-S. Do, S.-H. Wang, Sens Act B 2013; 185, 39.

[57] J. Gong, Y. Li, Z. Hu, Z. Zhou, Y. Deng, J Phys Chem C 2010; 114, 9970.

[58] I. Venditti, I. Fratoddi, M. V. Russo, A. Bearzotti, Nanotechnology 2013; 24, 155503.

[59] N. V. Bhat, A. P. Gadre, V. A. Bambole, J Appl Polym Sci 2000; 80, 2511.

[60] S.-W. Lee, N. Takahara, S. Korposh, D.-H. Yang, K. Toko, T. Kunitake, Anal Chem 2010; 82, 2228.

[61] M. Matsugushi, J. Io, G. Sugiyama, Y. Sakai, Synthetic Met 2002; 128, 15.

[62] A. Andreatta, Y. Cao, J. C. Chang, A. J. Heeger, P. Smith, Synthetic Met 1988; 26, 383.

[63] M. A. Kebede, M. E. Varner, N. K. Scharko, R. B. Gerber, J. D. Raff, J Am Chem Soc 2013; 135, 8606.

[64] S. Ji, Y. Li, M. Yang, Sens Act B 2008; 133, 644.

[65] W. T. Chen, K. M. E. Stewart, R. R. Mansour, A. Penlidis, Sens Act A 2015; 230, 63.

[66] B. Li, S. Santhanam, L. Schultz, M. Jefferies-El, M. C. Iovu, G. Sauvé, J. Cooper, R. Zhang, J. C. Revelli, A. G. Kusne, J. L. Snyder, T. Kowalewski, L. E. Weiss, R. D. McCullough, G. K. Fedder, D. N. Lambeth, Sens Act B 2007; 123, 651.

[67] M. Matsuguchi, K. Asahara, T. Mizukami, J Appl Polym Sci 2013; 127, 2529.

[68] J. N. Barisci, G. G. Wallace, M. K. Andrews, A. C. Partridge, P. D. Harris, Sens Act B 2002; 84, 252.

[69] W. Li, N. D. Hoa, Y. Cho, D. Kim, J.-S. Kim, Sens Act B 2009; 143, 132.

[70] C. W. Lin, Y. L. Liu, R. Thangamuthu, Sens Act B 2003; 94, 36.

[71] A. D. Rushi, K. P. Datta, P. S. Ghosh, A. Mulchandani, M. D. Shirsat, J Phys Chem C 2014; 118, 24034.

[72] S. Albonetti, R. Bonelli, R. Delaigle, C. Femoni, E. M. Gaigneaux, V. Morandi, L. Ortolani, C. Tiozzo, S. Zacchini, F. Trifirò, Appl Catal A-Gen 2010; 372, 138.

[73] L. M. T. Simplicio, S. T. Brandão, E. A. Sales, L. Lietti, F. Bozon-Verduraz, Appl Catal BEnviron 2006; 63, 9.

[74] G. Xie, P. Sun, X. Yan, X. Du, Y. Jiang, Sens Act B 2010; 145, 373.

[75] K.-I. Fujimoto, F. H. Ribeiro, M. Avalos-Borja, E. Iglasia, J Catal 1998; 179, 431. 
[76] M. Benounis, N. Jaffrezic-Renault, J.-P. Dustasta, K. Cherif, A. Abdelghani, Sens Act B 2005; 107, 32.

[77] P. Sun, Y. Jiang, G. Xie, X. Du, J. Hu, Sens Act B 2009; 141, 104.

[78] L. Garel, J.-P. Dustasta, A. Collet, Angew Chem Int Edit 1993; 32, 1169.

[79] K. M. E. Stewart, A. Penlidis, Macromol Sy 2013; 324, 11.

[80] P. Wolkoff, Int J Hyg Envir Heal 2013; 216, 371.

[81] C.-Y. Lee, C.-M. Chiang, Y.-H. Wang, R.-H. Ma. Sens Act B 2007; 122, 503.

[82] M. Ulmann, R. Kostecki, J. Augustynski, D. J. Strike, M. Koudelka-Hep, Chimia 1992; 46, 138.

[83] D. Nicolas-Debarnot, F. Poncin-Epaillard, Anal Chim Acta 2003; 475, 1.

[84] Z. Yang, Y. Huang, G. Chen, Z. Guo, S. Cheng, S. Huang, Sens Act B 2009; 140, 549.

[85] C. A. Papadopoulos, D. S. Vlachos, J. N. Avaritsiotis, Sens Act B 1996; 32, 61.

[86] E. M. Cordi, J. L. Falconer, J Catal 1996; 162, 104.

[87] H. Yu, T. Cao, L. Zhou, E. Gu, D. Yu, D. Jiang, Sens Act B 2006; 119, 512.

[88] R. B. Thompson, V. V. Ginzburg, M. W. Matsen, A. C. Balazs, Science 2001; 292, 2469. 